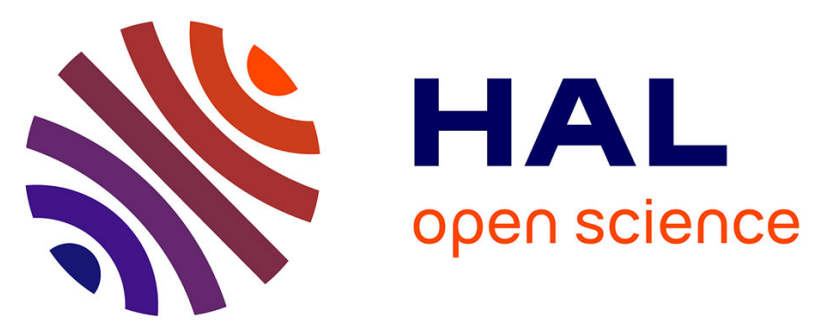

\title{
Hydronium Ions Stabilized in a Titanate-Layered Structure with High Ionic Conductivity: Application to Aqueous Proton Batteries
}

Seongkoo Kang, Arvinder Singh, Kyle G Reeves, Jean-Claude Badot, Serge Durand-Vidal, Christophe Legein, Monique Body, Olivier Dubrunfaut, Olaf J Borkiewicz, Benoit Tremblay, et al.

\section{To cite this version:}

Seongkoo Kang, Arvinder Singh, Kyle G Reeves, Jean-Claude Badot, Serge Durand-Vidal, et al.. Hydronium Ions Stabilized in a Titanate-Layered Structure with High Ionic Conductivity: Application to Aqueous Proton Batteries. Chemistry of Materials, 2020, 32 (21), pp.9458-9469. 10.1021/acs.chemmater.0c03658. hal-03118933

\section{HAL Id: hal-03118933 \\ https://hal.sorbonne-universite.fr/hal-03118933}

Submitted on 22 Jan 2021

HAL is a multi-disciplinary open access archive for the deposit and dissemination of scientific research documents, whether they are published or not. The documents may come from teaching and research institutions in France or abroad, or from public or private research centers.
L'archive ouverte pluridisciplinaire HAL, est destinée au dépôt et à la diffusion de documents scientifiques de niveau recherche, publiés ou non, émanant des établissements d'enseignement et de recherche français ou étrangers, des laboratoires publics ou privés. 


\title{
Hydronium lons Stabilized in a Titanate Layered Structure with High Ionic Conductivity: Application to Aqueous Proton Batteries
}

\author{
Seongkoo Kang, ${ }^{\mathrm{a}, \mathrm{b}}$ Arvinder Singh, ${ }^{\mathrm{b}, \mathrm{c}}$ Kyle G. Reeves, ${ }^{\mathrm{a}, \mathrm{b}}$ Jean-Claude Badot, ${ }^{\mathrm{b}, \mathrm{d}}$ Serge Durand-Vidal, ${ }^{\mathrm{a}, \mathrm{b}}$ \\ Christophe Legein, ${ }^{\mathrm{e}}$ Monique Body, ${ }^{\mathrm{e}}$ Olivier Dubrunfaut, ${ }^{\mathrm{f}}$ Olaf J. Borkiewicz, ${ }^{\mathrm{g}}$ Benoît Tremblay, ${ }^{\mathrm{h}}$ \\ Christel Laberty-Robert, ${ }^{\mathrm{b}, \mathrm{c}}$ and Damien Dambournet ${ }^{\mathrm{a}, \mathrm{b}^{*}}$
}

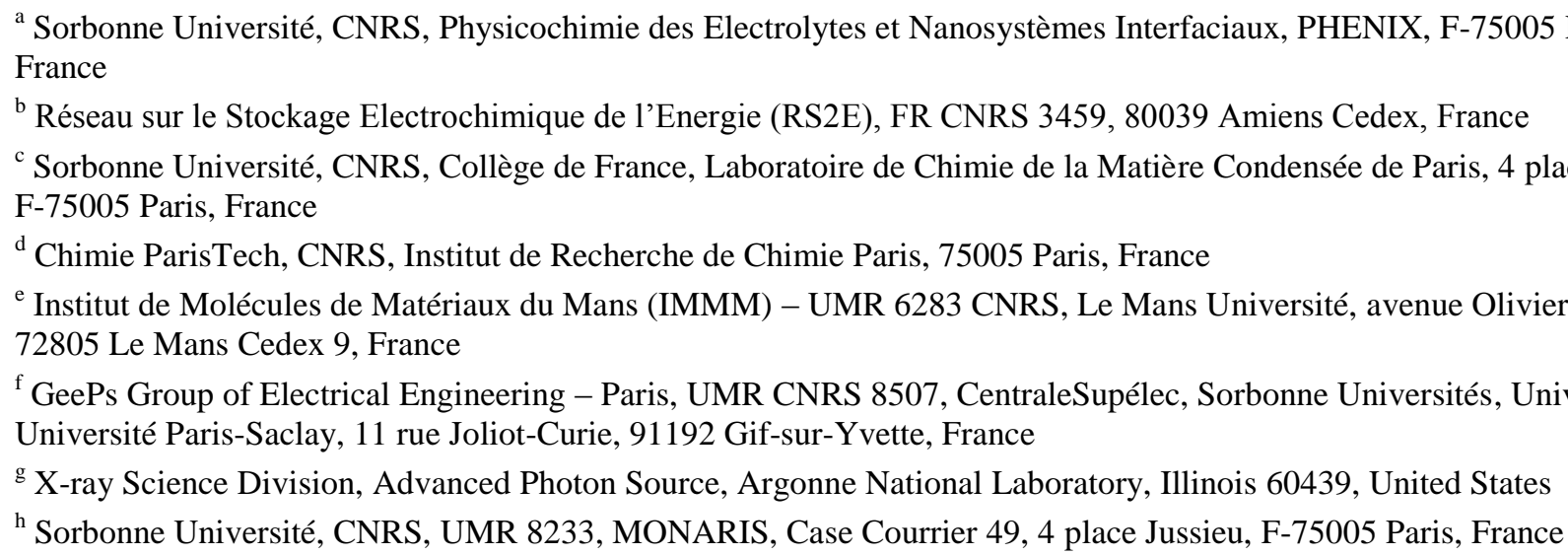

\begin{abstract}
Proton chemistry is a fascinating field with both fundamental and applied aspects. The development of solid-state proton conductors relying on abundant elements could help bring those two aspects. In this scope, we synthesized a disordered structure which, as revealed by the real-space refinement of the pair distribution function, has been identified to be the trititanate arrangement. The layered structure is stabilized by the presence of hydronium ions and water molecules located in the interlayer space. This compound displays a high ionic conductivity of $4 \cdot 10^{-2} \mathrm{~S} / \mathrm{m}$ with an activation energy of $0.24 \mathrm{eV}$, assigned to $\mathrm{H}^{+}$mobility as shown by broadband dielectric spectroscopy. Proton mobility was further evidenced by solid-state ${ }^{1} \mathrm{H}$ NMR. DFTcalculations revealed that proton transfer occurs both within the interlayer space and with terminal oxide of the titanate framework through a Grotthuss-based mechanism rationalizing the high conductivity measured experimentally. Finally, we investigated the electrochemical properties with respect to the proton as a charge carrier using a proton-free $(\mathrm{KCl})$ and proton-donor (buffer acetic acid) electrolytes. The results showed that the structure can reversibly intercalate protons at a very high rate opening exiting perspectives on the development of negative electrode materials for aqueous proton batteries. Overall, this study helps better understanding the proton transfer mechanism occurring in a confined layered type structure.
\end{abstract}

\section{INTRODUCTION}

New battery technologies based on charge carriers other than lithium such as $\mathrm{Na}^{+}, \mathrm{K}^{+}, \mathrm{Mg}^{2+}$, and $\mathrm{Ca}^{2+}$, are attractive choices due to their high abundances and theoretical capacities. ${ }^{1-7}$ In this scope, protons are also unique intercalants, which have received little attention despite being abundant, lighter, and smaller than the above-mentioned metal ions. ${ }^{8-10}$ Proton based batteries could represent an exceptional solution for largescale energy storage that needs to be cost-effective and safe. Recent studies demonstrate that some hosts could reversibly intercalate proton in aqueous electrolytes, which evokes the eagerness for developing proton based aqueous batteries. ${ }^{8,11,12}$ Among the materials explored for proton intercalation, $\mathrm{TiO}_{2}$ has attracted the most attention because it is a lightweight, abundant, nontoxic, and corrosion-resistant functional material. ${ }^{13}$ It is shown that polymorphs of $\mathrm{TiO}_{2}$ can electrochemical- ly intercalate protons with the reduction of $\mathrm{Ti}^{\mathrm{IV}}$ to $\mathrm{Ti}^{\mathrm{III}}$ by an application of negative bias in acidic conditions. ${ }^{14-17}$ Recently, Kim et al. observed extremely fast (a few seconds) protoncoupled charge storage in nanostructured $\mathrm{TiO}_{2}$ in a mild acidic aqueous condition ( $\mathrm{pH}$ 5) opening new opportunities to the development of eco-friendly batteries. ${ }^{18}$ Furthermore, it is reported that the presence of ions/molecules as interlayer spacers (pillars between layers) in layered materials facilitates the proton intercalation. For example, Fleischmann et al. ${ }^{19}$ investigated the electrochemical proton intercalation properties in layered hydrogen titanates in which, structural protons are bound to both bridging and terminal oxygen as hydroxyl groups and serve as an interlayer spacer for titanate layers. The presence of these structural protons keeps the titanate layers well-separated and significantly increases the proton intercalation (in $1 \mathrm{M} \mathrm{H}_{2} \mathrm{SO}_{4}$ ) capacity to $82 \mathrm{mAh} / \mathrm{g}$ than $\mathrm{TiO}_{2}$ 
( $<15 \mathrm{mAh} / \mathrm{g}$ ) thus opening interesting perspectives in developing layered materials for proton-based batteries. Similarly, Wu et $a l .{ }^{9}$ demonstrated that structural water molecules in a Prussian blue analogue enabled it to obtain high-power characteristics owing to the hydrogen-bonding network that facilitates proton intercalation via Grotthuss proton conduction. Consequently, layered materials featuring an improved interlayer space with the presence of ions and/or structural water have been increasingly investigated to understand how the presence of these ions/molecules affects the electrochemical properties. $^{20}$ In particular, the layered oxide materials possessing intrinsic high proton conductivity with the presence of structural protons/water (interlayer spacers) are of great interest as they could provide enhanced electrochemical properties with respect to proton intercalation. ${ }^{21}$

Moreover, layered titanate materials featuring protons and intrinsic ionic conductivity have been previously reported. ${ }^{22-24}$ Overall, the synthesis method employed in these reports relied on the protocol first reported by Kasuga et al. ${ }^{25}$ Typically, this method consists of hydrothermal treatment of titanium dioxide precursor (which can be rutile, ${ }^{25}$ anatase, ${ }^{26}$ or amorphous $\mathrm{TiO}_{2}{ }^{27}$ ) in a highly concentrated $\mathrm{NaOH}$ medium followed by an ionic-exchange $\mathrm{Na}^{+}-\mathrm{H}^{+}$with the use of mild acid treatment. During the acid treatment, $\mathrm{Na}^{+}$inside the interlayer is exchanged with $\mathrm{H}^{+}$and concomitantly morphological and structural changes occurred leading, in most cases, to samples featuring complex x-ray diffraction patterns with broad Bragg peaks, typically encountered for disordered/nanoscaled structure. Hence, it is often difficult to describe the structure of these materials as well as to characterize ionic transport/interaction occurring within the interlayer space.

In this work, we embark on re-investigating the structural features of a layered titanate featuring interlayer space consisting of hydronium ions and water molecules. The synthesis method employed used a modified version of the protocol developed by Kasuga, with the use of a titanium molecular precursor to favor its reactivity toward $\mathrm{NaOH}$. The assynthetized compound featured a high ionic conductivity of $4 \cdot 10^{-2} \mathrm{~S} / \mathrm{m}$, suggesting high proton mobility within the identified trititanate structure. Evidence for the stabilization of hydronium ions and $\mathrm{H}^{+}$-hopping was provided by solid-state ${ }^{1} \mathrm{H}$ NMR and dielectric spectroscopy. The impact of H-titanate on electrochemical insertion of protons was investigated. DFTcalculations suggested that proton mobility occurs via a Grotthuss mechanism. Owing to intrinsic high $\mathrm{H}^{+}$-mobility, the electrochemical properties with respect to the proton as charge carrier were investigated highlighting great opportunities in developing high power negative electrode for aqueous rechargeable batteries.

2D materials featuring interlayer space with ions and/or structural water have been increasingly investigated to understand how confinement affects the electrochemical properties, particularly in transition metal oxides. ${ }^{28,29}$ Moreover, materials with intrinsic high proton conductivity could provide enhanced electrochemical properties with respect to proton intercalation. ${ }^{21}$ Hence, a structure featuring an interlayer composed of hydronium/water molecules could provide enhanced electrochemical properties. Finally, such a system could help to better understand the effect of nanoconfinement on the proton chemistry, particularly on the transfer mechanism. ${ }^{28,30-34}$

\section{EXPERIMENTAL SECTION}

Synthesis. A solution of $26 \mathrm{~mL}$ of $10 \mathrm{M} \mathrm{NaOH}$ was added to $4 \mathrm{~mL}$ of Titanium (IV) isopropoxide (> 97\%, Sigma-Aldrich) under stirring and sealed in a $45 \mathrm{~mL}$ Teflon-lined autoclave. The mixture was heated at $90{ }^{\circ} \mathrm{C}$ for $12 \mathrm{~h}$. Synthesized Natitanate was separated by centrifugation and washed with water. The obtained powder was treated with $1 \mathrm{M} \mathrm{HCl}$ under stirring for $20 \mathrm{~min}$. The sample was washed with water and recovered by centrifugation and then dried at $80{ }^{\circ} \mathrm{C}$ overnight. For comparison purposes, we synthesized $\mathrm{H}$-titanate using a solid precursor, which is anatase $\mathrm{TiO}_{2}$ powder. In a solution of $26 \mathrm{~mL}$ of $10 \mathrm{M} \mathrm{NaOH}$, we added $1.07 \mathrm{~g}$ of $\mathrm{TiO}_{2}$ anatase powder under stirring. The mixture was heated at $150{ }^{\circ} \mathrm{C}$ for $12 \mathrm{~h}$. Similar aforementioned protocols were then used.

X-ray diffraction. Powder x-ray diffraction measurements were done with Rigaku diffractometer in Bragg-Brentano geometry equipped with $\mathrm{Cu} \mathrm{K} \alpha$ radiation.

Pair distribution function. High-energy synchrotron $\mathrm{x}$-ray diffraction $(\lambda=0.2128 \AA)$ data were collected at the 11-ID-B beamline at the Advanced Photon Source at Argonne National Laboratory. The raw 2D total scattering data were integrated into one-dimensional diffraction data using FIT2D. ${ }^{35}$ Fourier transformation and correction of PDFs were done with PDFgetX3 ${ }^{36}$ PDF refinements were performed using PDFgui software. $^{37}$ The quality of the refinement is quantified by the reliability factor weighted $\mathrm{R}$-value, denoted as $\mathrm{R}_{w}$. The $\mathrm{R}$ value describes the difference between the experimental observation (data) and the calculated value (fit) for a single data point. The $\mathrm{R}_{w}$ is the $\mathrm{R}$-value weighted for data point $i$, and is given by the formula:

$$
\mathrm{R}_{w}=\sqrt{\frac{\sum_{i=1}^{\mathrm{N}} w\left(r_{i}\right)\left[\mathrm{G}_{\text {obs }}\left(r_{i}\right)-\mathrm{G}_{\text {calc }}\left(r_{i}\right)\right]^{2}}{\sum_{i=1}^{\mathrm{N}} w\left(r_{i}\right) \mathrm{G}_{o b s}^{2}\left(r_{i}\right)}}
$$

with $\mathrm{G}_{o b s}$ and $\mathrm{G}_{c a l c}$ being the observed (data) and calculated (fit) PDF and $w\left(r_{i}\right)$ the weight for each data point.

Transmission electron microscopy. The analysis was performed with JEOL 201 UHR microscope operating at $200 \mathrm{kV}$ equipped with a TCD camera. Scanning electron microscopy was performed with Hitachi $\mathrm{Su}-70$ at $5 \mathrm{kV}$.

Thermal analysis. Thermogravimetric analysis data were collected with TA instruments TGA550 analyzer. The analysis was performed between $25^{\circ} \mathrm{C}$ and $600{ }^{\circ} \mathrm{C}$ at a heating ramp of $1{ }^{\circ} \mathrm{C} /$ min under $\mathrm{N}_{2}$ atmosphere.

FT-IR. Infrared spectra of the samples were recorded using an ATR diamond crystal accessory on a Bruker Equinox 55 spectrometer equipped with a $\mathrm{Ge} / \mathrm{KBr}$ beamsplitter and a liquid nitrogen-cooled MCT detector under ambient conditions and with a spectral resolution of $4 \mathrm{~cm}^{-1}$.

Conductometric titration. Into a dispersion of $0.1 \mathrm{~g}$ of $\mathrm{H}-$ titanate in $16 \mathrm{~mL}$ of ultrapure water, we added step-by-step 0.1 $\mathrm{mL}$ of $1 \mathrm{M} \mathrm{NaOH}$. The evolution of the resistivity was measured using QuadTech 7600 Plus Precision LCR meter and Fisherbrand Accumet four-cell conductivity/ATC probes (Cell constant $\left.=10 \mathrm{~cm}^{-1}\right)$. The measurements were performed at 1 $\mathrm{kHz}$ which was determined by finding the frequency where the imaginary part of the impedance is neglected with an impedance measurement swept between $1 \cdot 10^{2} \mathrm{~Hz}$ and $2 \cdot 10^{6} \mathrm{~Hz}$.

${ }^{1} \mathrm{H}$ MAS NMR. ${ }^{1} \mathrm{H}$ solid-state magic angle spinning (MAS) NMR experiments were performed on a Bruker Avance 300 
spectrometer operating at 7.0 T $\left({ }^{1} \mathrm{H}\right.$ Larmor frequency of 300.2 $\mathrm{MHz}$ ), using a $1.3 \mathrm{~mm}$ CP-MAS probe head. The room temperature ${ }^{1} \mathrm{H}$ MAS spectra were recorded using a Hahn echo sequence with an interpulse delay equal to one rotor period. The $90^{\circ}$ pulse length was set to $2.4 \mu \mathrm{s}, 160$ transients were accumulated with recycle delays of $20 \mathrm{~s} .{ }^{1} \mathrm{H}$ spectra are referenced to TMS and were fitted using the DMFit software. ${ }^{38}$

Broadband Dielectric Spectroscopy. The complex conductivity and permittivity of the samples were measured between 50 and $10^{10} \mathrm{~Hz}$ using Agilent E8364B PNA Network Analyzer $\left(10^{7}\right.$ to $\left.10^{10} \mathrm{~Hz}\right)$ and Agilent E4990A Impedance Analyzer (50 to $10^{8} \mathrm{~Hz}$ ). The sample was prepared by pressing powder into the pellets at $0.7 \mathrm{GPa}$ (diameter $=3 \mathrm{~mm}$, thickness $=1 \mathrm{~mm}$ ) and metalized with silver paint. The pellet was placed between the inner conductor and a short-circuit of a coaxial APC7 cell.

DFT-calculations. Supercells starting from the structure determined by PDF refinement were used, to which hydronium ions were added to what were deemed as the most likely positions. To simplify the calculations, water molecules - expected to be present within the structure-were omitted. The resulting supercell $\mathrm{Ti}_{12} \mathrm{O}_{28}\left(\mathrm{H}_{3} \mathrm{O}\right)_{8}$ was simulated using a triclinic unit cell defined by a $=15.77732 \AA, \mathrm{b}=3.85755 \AA$, $\mathrm{c}=9.39849 \AA$, $\alpha=90.00000^{\circ}, \beta=101.5000^{\circ}$, and $\gamma=90.00000^{\circ}$. Fixing the positions of the titanium atoms as well as the unit cell, a geometry optimization calculation was computed using the CP2K code. $^{39}$ DZVP-MOLOPT-SR-GTH ${ }^{40}$ basis sets were used to construct the Kohn-Sham wave functions with a plane wave cutoff of 400 Rydberg. Goedecker-Teter-Hutter pseudopotentials $^{41}$ were used, where Ti atoms were represented explicitly using $3 s^{2} 3 p^{6} 3 d^{2} 4 s^{2}$ electronic orbitals, and $O$ atoms were represented using $2 \mathrm{~s}^{2} 2 \mathrm{p}^{4}$ electronic orbitals. The generalized-gradient approximation PBE was used as the exchange-correlation functional ${ }^{42}$. Simulations were charge neutral. The calculation was performed with periodic boundary conditions using $\Gamma$-point sampling.

Electrochemistry. Electrochemical experiments were conducted in a closed 3-electrode cell with biologic potentiostat and EC-lab interface in an ambient condition. The electrode was prepared by mixing $80 \mathrm{wt} . \%$ of synthesized material with 20 wt.\% of conductive carbon black (TIMCAL Graphite \& Carbon Super P). The mixture was first dispersed in $1 \mathrm{~mL}$ of tetrahydrofuran (Anhydrous, > $99.9 \%$, inhibitor-free, SigmaAldrich) and sonicated for $15 \mathrm{~min}$. Subsequently, $65 \mu \mathrm{L}$ of Nafion 117 solution (5\% in a mixture of lower aliphatic alcohols and water, Fluka) and sonicated for $15 \mathrm{~min}$. A volume corresponding to $40 \mu \mathrm{L}$ of the slurry was deposited on titanium foil (> $95 \%$, Alfa Aesar) of $0.25 \mathrm{~cm}^{2}$ surface. The mass loading was around $2.4 \mathrm{mg} / \mathrm{cm}^{2}$. The electrochemical properties were characterized in a three-electrode cell with $\mathrm{Ag} / \mathrm{AgCl}$ and Pt electrodes employed as reference and counter electrode, respectively. The electrochemical measurements were performed in $1 \mathrm{M} \mathrm{KCl}$ and $1 \mathrm{M}$ acetic acid buffer solution ( $\mathrm{pH}$ 5) as the electrolytes. The electrolyte solution in the cell was thoroughly deaerated by argon (for at least 30 minutes) before each experiment to avoid faradaic contribution arising from the reduction of the dissolved $\mathrm{O}_{2}$ and a constant flux of argon was maintained above the solution during all electrochemical measurements. ${ }^{43}$ The reproducibility of the electrochemical results was checked by repeating measurements at least five times using different cells.

\section{RESULTS AND DISCUSSION}

To synthesize a layered structure containing a large content of protons, we revisited the method proposed by Kasuga et al, ${ }^{25,44}$ which consists of treating particles of $\mathrm{TiO}_{2}$ in a highly basic solution under hydrothermal conditions followed by a sodiumproton exchange reaction. To increase the reactivity of the $\mathrm{Ti}$ precursor, we replaced the solid by a molecular precursor, namely titanium isopropoxide (see Experimental Section). The obtained Na-titanate was then treated with an acidic solution $(\mathrm{HCl}, 1 \mathrm{M})$ to exchange sodium by protons (H-titanate). The typical $\mathrm{x}$-ray diffraction pattern (XRD) of $\mathrm{H}$-titanate shown in Figure 1, features broad and poorly defined Bragg peaks indicating nano-sized particles and/or disordered structure. This type of diffraction pattern is commonly reported for a similar type of material employing an ion-exchange reaction. ${ }^{45,46}$ The diffraction line at around $9.77^{\circ}(2 \theta)$ is characteristic of a layered type structure. In an attempt to index the diffraction pattern, we compared it with known layered titanate compounds as found in the ICSD database ${ }^{47,48}$. The models used are layered structures where the slabs are comprised of either corrugated layers $(C 2 / m)^{48}$ or flat layers $(\text { Immm })^{47}$ also known as trititanate and lepidocrocite-type titanate, respectively (Figure $1 \mathrm{~A}$ and $\mathrm{B})$. At first glance, the pattern seems closer to the corrugated structure, particularly with the indexation of (110) and (020) lines.
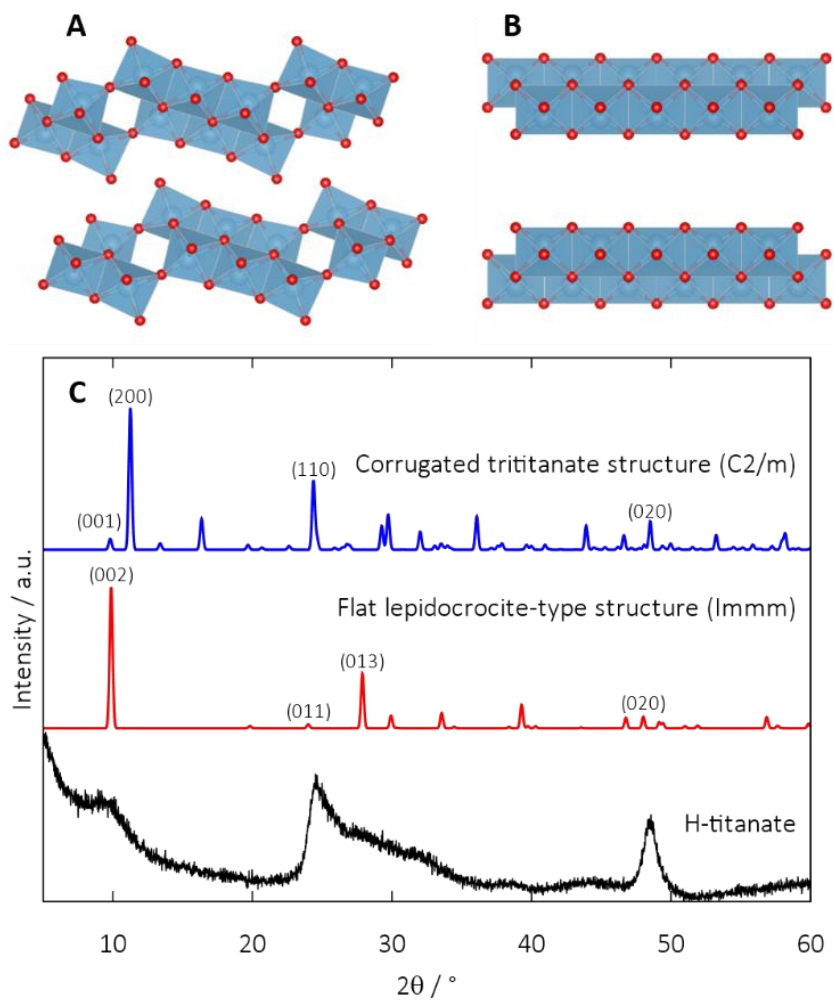

Figure 1. Structural representation of A) corrugated titanate (trititanate) and B) flat titanate (lepidocrocite) and C) x-ray diffraction pattern of as-synthesized $\mathrm{H}$-titanate and simulated XRDs of the different reference layered titanate structures

Electron microscopy was used to detail morphological features. $\mathrm{H}$-titanate is composed of aggregates of about $0.5 \mu \mathrm{m}$ of diameter (Figure S1). Aggregates are composed of fiber-type particles with a thickness of about 3-5 nm (Figure 2). As the fibers are strongly aggregated, it is difficult to determine their length. 
By zooming in on the TEM image, we can observe stacks of three to five layers constituting the fibers. The interlayer spacing measured from the image is around $9 \AA$. This d-spacing can be assigned to the (200) line of the corrugated structure and the corresponding Bragg peak at $9.77^{\circ}(2 \theta)$. Hence, we assigned the broadness of the peak to a size effect with few numbers of layers composing the 1D morphology.
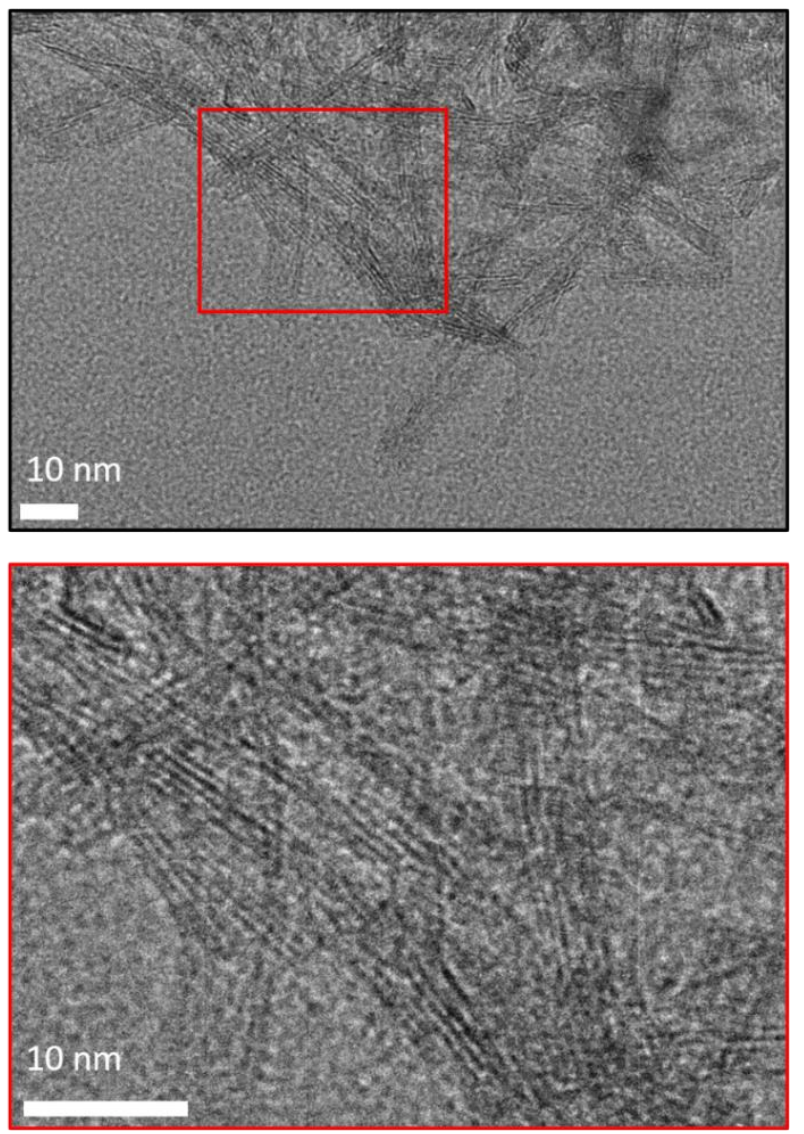

Figure 2. Transmission electron microscopy images of H-titanate showing 1D morphology constituted with a stack of layers (bottom: zoom-in of the red square).

To identify the structural features of H-titanate, we used highenergy x-ray scattering. The collected data were Fourier transformed to atomic pair distribution functions (PDF) providing a histogram of atomic pair correlation where each peak corresponds to the distance of the atomic pair. PDF is a powerful tool to study local to average range ordering of disordered and/or nanosized materials. ${ }^{49,50}$

Atomic correlations of $\mathrm{H}$-titanate could be divided into shortrange order $<15 \AA$ related to intra and interlayer contributions and long-range order $>15 \AA$ showing a periodicity that may be related to $1 \mathrm{D}$ morphology (Figure S2). We attempted to refine the PDF of H-titanate using different structural models (Figure 3) including the lepidocrocite and several corrugated structures. Overall, a better agreement between the calculated and experimental data was found for the trititanate structure (see reliability factor $\mathrm{R}_{\mathrm{w}}$ values). Particularly, the trititanate model better fit the local structure with distances related to $\mathrm{Ti}-$ $\mathrm{O}(1.921 \AA)$ in $\mathrm{TiO}_{6}$ octahedra, Ti-Ti between edge-sharing (3.122 $\AA$ ) and corner-sharing (3.709 $\AA$ ) octahedra. In the trititanate, the structure displays a corrugated structure where slabs of three edge-sharing $\mathrm{TiO}_{6}$ octahedra are interconnected through corner-sharing (Figure $1 \mathrm{~A}$ ). It is the reason why the corrugated structure is also called trititanate. Meanwhile, the lepidocrocite-type structure has flat slabs constituted of edgesharing octahedra. Consequently, trititanate contains more corner-sharing Ti-Ti than the lepidocrocite-type titanate. ${ }^{51}$ As a result, the intensity of the corner-sharing peak is higher than the edge-sharing peak, which better fit the experimental data. The refined unit cell parameters are $a=15.8673$ (0.13) $\AA$, $b=$ $3.774(0.024) \AA$ and $c=9.42972(0.1) \AA\left(\alpha=90^{\circ}, \beta=101.5^{\circ}\right.$, $\gamma=90^{\circ}$ ). Comparing with the model structure (ICSD Coll. Code 5455), the structure shrank along the $a$-axis and elongated along the $c$-axis ( $a=15.99 \AA, b=3.738 \AA$ and $c=9.172 \AA$ ). We further attempted to locate oxygen atoms within the interlayer space, which did not produce any significant improvement of the fit suggesting that the interlayer is probably highly disordered.

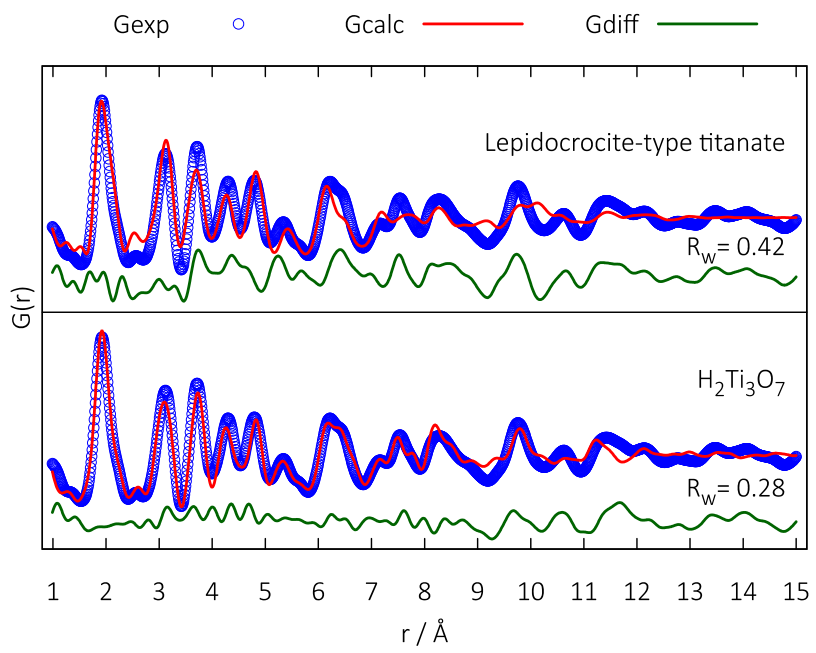

Figure 3. PDF refinements of H-titanate using the lepidocrocite and trititanate structural models.

\section{Determination of the chemical formula}

The crystal cell contains three titanium and seven oxygen so that there are two negative charges that should be compensated by the presence of protons, i.e., hydronium ions. The theoretical formula is $\left(\mathrm{H}_{3} \mathrm{O}\right)_{2} \mathrm{Ti}_{3} \mathrm{O}_{7} \cdot \mathrm{nH}_{2} \mathrm{O}$ where $\mathrm{n}$ is assigned to structural water molecules. The later was postulated from the thermogravimetric analysis. To assess the chemical composition, we employed different techniques including conductimetric titration to determine the content of protons. The conductimetric titration (Figure S3) showed a deficiency of protons as compared to the theoretical chemical formula. Hence, we hypothesized that such deficiency of $\mathrm{H}_{3} \mathrm{O}^{+}$is compensated by the presence of oxygen vacancies, which can be expressed by the following general formula $\left(\mathrm{H}_{3} \mathrm{O}\right)_{2-x} \mathrm{Ti}_{3} \mathrm{O}_{7-}$ ${ }_{x / 2} \square_{x / 2} \cdot n\left(\mathrm{H}_{2} \mathrm{O}\right)$, where $\square$ represents a vacancy.

Thermogravimetric analysis (TGA) was performed from 25 to $600{ }^{\circ} \mathrm{C}$ at a heating ramp of $1{ }^{\circ} \mathrm{C} / \mathrm{min}$ under $\mathrm{N}_{2}$ (Figure $4 \mathrm{~A}$ ). The total weight loss is $22 \%$, which evidences the hydrated/protonated state of the layered structure. We observed an overlapping two-steps dehydration process within the 25$100{ }^{\circ} \mathrm{C}$ and $100-450{ }^{\circ} \mathrm{C}$ regions accounting for 13 and $9 \mathrm{wt} . \%$, respectively. The thermal behavior of $\mathrm{H}$-titanate is very similar to the one observed by Sasaki et al., ${ }^{47}$ on lepidocrocite $\mathrm{H}_{x} \mathrm{Ti}_{2-x / 4} \square_{x / 4} \mathrm{O}_{4} \cdot \mathrm{H}_{2} \mathrm{O}$. Accordingly, we assigned the first step to the departure of physisorbed and structural water, followed by the departure of hydronium ions. 
Based on titration and thermal analysis, we propose the following chemical formula $\left(\mathrm{H}_{3} \mathrm{O}\right)_{1.35} \mathrm{Ti}_{3} \mathrm{O}_{6.67} \square_{0.33} \cdot 1.73 \mathrm{H}_{2} \mathrm{O}(\mathrm{M}=$ $307.21 \mathrm{~g} / \mathrm{mol})$. We note that the amount of structural water $\left(1.73 \mathrm{H}_{2} \mathrm{O}\right)$ includes a proportion of physisorbed water molecules which, are difficult to accurately quantify.

The thermal stability of the structure was investigated using ex-situ X-ray diffraction analysis on heat-treated samples (Figure S4). It showed that at $\mathrm{T}=100^{\circ} \mathrm{C}$, the (200) line slightly shifts to a higher $2 \theta$ value suggesting a contraction of the layered structure in agreement with the release of structural water molecules. At $150^{\circ} \mathrm{C}$, we observed diffuse peaks located at around $10-15^{\circ}(2 \theta)$, which suggest the formation of $\mathrm{TiO}_{2}-(\mathrm{B})$ as well as peaks related to anatase $\mathrm{TiO}_{2}$. At higher temperatures, the structure progressively transformed to anatase. Formation of $\mathrm{TiO}_{2}$-(B) upon calcination of trititanate due to the structural rearrangement related to the amount of water in the interlayer was reported in many studies. ${ }^{52-56}$ Wang et al. ${ }^{57}$ reported also the direct crystallization of anatase upon calcination of the trititanate. This points out that the chemical formula, hence the structural arrangement, impacts the thermal behavior of the structure.

The hydrated state of the sample was confirmed by FT-IR spectroscopy (Figure 4B). The latter characterizes O-H vibration modes. The spectrum measured at room temperature in ambient conditions shows a large band between 2800 and $3500 \mathrm{~cm}^{-1}$ and a sharp peak at $1629 \mathrm{~cm}^{-1}$ assigned to the stretching $v$ and deformation $\delta$ of $\mathrm{O}-\mathrm{H}$ vibration modes, respectively. The band at $1629 \mathrm{~cm}^{-1}$ can be attributed to both structural water and/or hydronium ions and therefore cannot be used to discriminate both species. ${ }^{47}$ The large band located between 2800 and $3500 \mathrm{~cm}^{-1}$ is characteristic of hydrogen bonds.
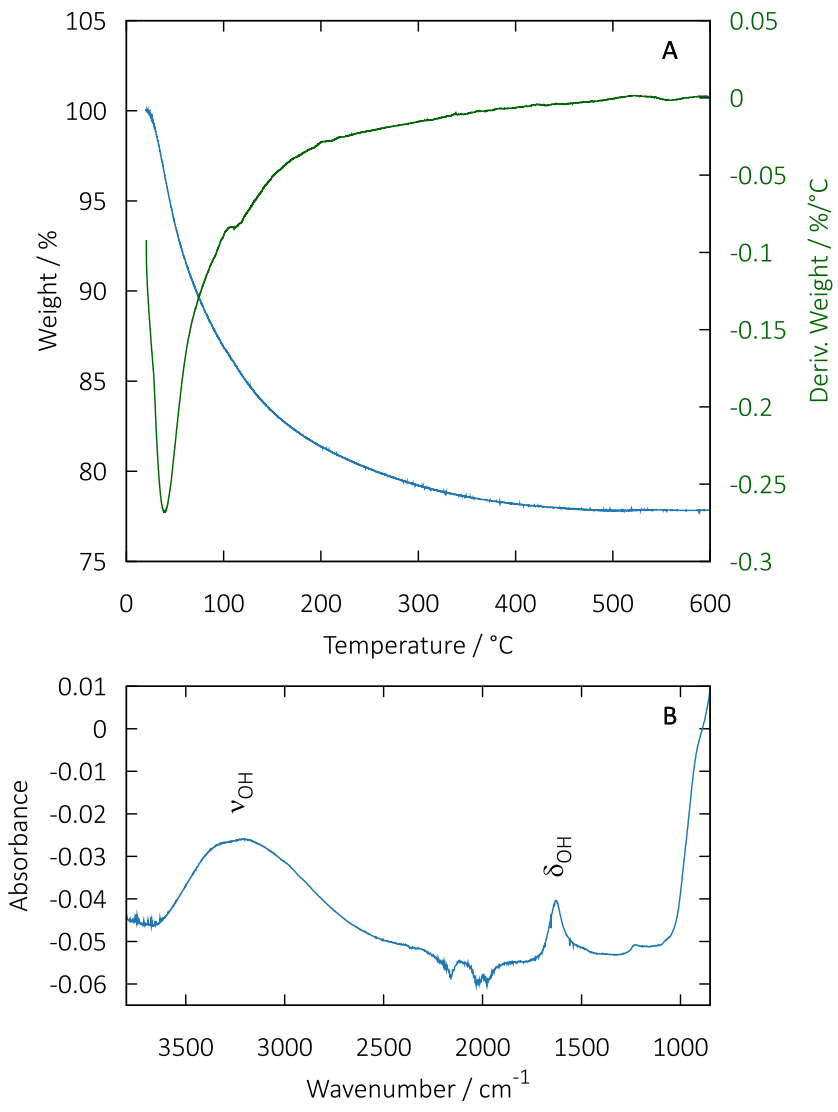

Figure 4. (A) Thermogravimetric (blue) and derivative (green) curves recorded under $\mathrm{N}_{2}$, at $1{ }^{\circ} \mathrm{C} / \mathrm{min}$. (B) ATR FT-IR spectrum of H-titanate.

\section{Characterization of interlayer hydronium ions and water molecules}

The local environment of hydrogen atoms was further investigated using ${ }^{1} \mathrm{H}$ solid-state MAS NMR (Figure 5). The spectrum consists essentially of a broad contribution (full width at half maximum (FWMH) equal to $760 \mathrm{~Hz}$ ), slightly asymmetric (two lines are needed to reconstruct it properly) with a maximum at $\sim 6.4 \mathrm{ppm}$. Such width may be due to a distribution of proton environments in the material and thus to the distribution of chemical shifts and/or to the strong homo nuclear ${ }^{1} \mathrm{H}-{ }^{1} \mathrm{H}$ dipolar coupling which is not averaged to zero despite the high spinning frequency (the FWMH decreases from $\sim 1100 \mathrm{~Hz}$ to $760 \mathrm{~Hz}$ as the spinning frequency increases from $44 \mathrm{kHz}$ to $60 \mathrm{kHz}$ ). In addition to the main line at 6.3 ppm, a value similar to that of the resonance assigned to interlayer water molecules in layered titanate, ${ }^{58}$ the reconstruction of the main contribution highlights a second NMR resonance at $8.1 \mathrm{ppm}$. This value is close to $9 \mathrm{ppm}$, reported for hydrated hydronium ions in a zeolite. ${ }^{59}$ The relative intensities of these two resonances are difficult to distinguish, and thus, do not respect the proportions of protons in $\mathrm{H}_{2} \mathrm{O}$ and $\mathrm{H}_{3} \mathrm{O}^{+}$. We therefore assume that resonances of $\mathrm{H}_{3} \mathrm{O}^{+}$ions and $\mathrm{H}_{2} \mathrm{O}$ molecules, broadened by disorder and residual dipole coupling, merge due to the rapid exchange of protons between these species. Finally, there are two, low-intensity resonances, at 0.85 and $1.26 \mathrm{ppm}$, that can be assigned to a small amount of terminal $\mathrm{OH}$ groups, $\mathrm{Ti}-\mathrm{OH} .^{58,60}$

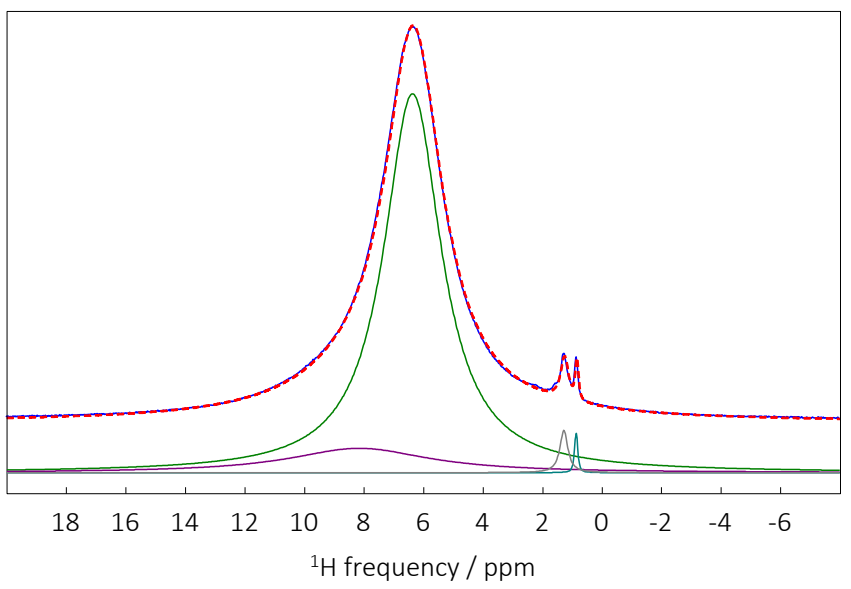

Figure 5. Experimental (blue) and fitted (red dashed line) $1 \mathrm{H}$ MAS $(60 \mathrm{kHz})$ NMR spectrum of $\mathrm{H}$-titanate. The individual resonances used for the fit are shown below (see Table 1).

Table 1. Isotropic chemical shifts ( $\left.\delta_{\text {iso }}, \mathrm{ppm}\right)$, line widths (LW, ppm), relative intensities (I, \%), of the NMR resonances used for the fit of the ${ }^{1} \mathrm{H}$ MAS $(60 \mathrm{kHz})$ NMR spectrum of $\mathrm{H}$-titanate.

\begin{tabular}{ccc}
\hline$\delta_{\text {iso }}(\mathrm{ppm})$ & $\mathrm{LW}(\mathrm{ppm})$ & $\mathrm{I}(\%)$ \\
\hline 0.85 & 0.13 & 0.4 \\
1.26 & 0.31 & 1.3 \\
6.30 & 2.30 & 84.9 \\
\hline
\end{tabular}


8.10

5.70

13.4

Broadband dielectric spectroscopy (BDS) enables to probe different relaxation phenomena in inorganic materials ranging from grain boundary polarization to molecular motions, by accessing the time-dependent charge-density fluctuation represented by pulsation $\omega(\omega=2 \pi v, v$ being the frequency expressed in $\mathrm{Hz}$ ) dependent complex conductivity $\sigma(\omega)$, resistivity $\rho(\omega)$ and permittivity $\varepsilon(\omega)$ :

$$
\sigma(\omega)=\rho(\omega)^{-1}=i \omega \varepsilon_{0} \varepsilon(\omega)
$$

where $\varepsilon_{0}$ is the vacuum permittivity. The relaxation time of the fluctuation depends on the relaxation mechanism of different phenomena such as reorientation of dipolar species, local charge hopping, and interfacial charge fluctuation. ${ }^{61}$

The complex resistivity of $\mathrm{H}$-titanate was measured under ambient conditions (without controlling the relative humidity) and is represented with a Nyquist plot of the imaginary part $\rho^{\prime \prime}(\omega) v s$. the real part $\rho^{\prime}(\omega)$ (Figure 6). Bulk conductivity $\sigma_{g}$ was assessed by fitting the complex resistivity leading to $4 \cdot 10$ ${ }^{2} \mathrm{~S} / \mathrm{m}$, suggesting high proton mobility within the trititanate structure. Such a value is about two orders of magnitude higher than reported values (Table S1). ${ }^{22-24,62}$

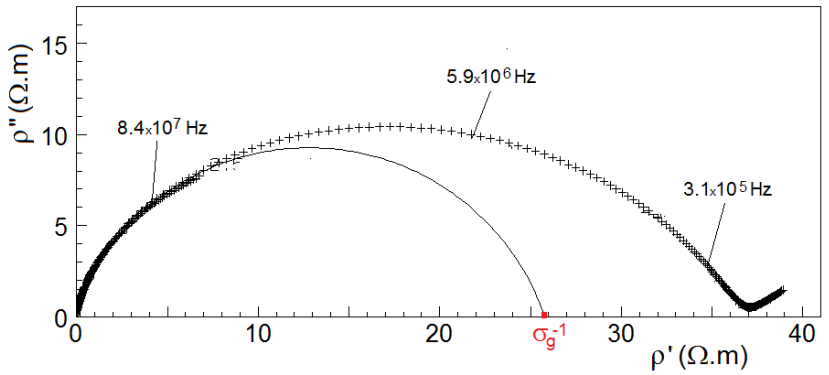

Figure 6. Plot of the imaginary part $\rho$ ' $(\omega)$ vs. the real part $\rho^{\prime}(\omega)$ of the complex resistivity of $\mathrm{H}$-titanate measured at $295 \mathrm{~K}$ under ambient conditions.

For the sake of comparison, we synthesized H-titanate using a solid precursor with synthesis conditions typically employed in the literature (see Experimental Section). The assynthesized product (Figure S5) presented a RT bulk ionic conductivity of $3 \cdot 10^{-3} \mathrm{~S} / \mathrm{m}$, which is lower than the value obtained using molecular precursor. Hence, the use of titanium alkoxide as a precursor is decisive in achieving high proton conductivity.

To probe molecular motions occurring within the layered structure, we analyzed the frequency-dependent complex permittivity represented with the Nyquist plot. As the relaxations are additive due to vectoral character, they can be evidenced by decomposing the Nyquist permittivity plot and contributions thereafter were denoted as "P" for part. Dielectric relaxations were fitted with the Cole-Cole function ${ }^{63}$ represented by a circular arc centered below the baseline:

$$
\varepsilon(\omega)=\varepsilon_{\infty}+\frac{\varepsilon_{l}-\varepsilon_{\infty}}{1+(i \omega \tau)^{1-\alpha}}
$$

where $\varepsilon_{l}$ and $\varepsilon_{\infty}$ are respectively lower and higher frequency limits of the permittivity. The relaxation time $\tau$ is related to the characteristic timescale of dipolar motions. The exponent parameter $\alpha(0 \leq \alpha \leq 1)$ measures the degree of departure from the Debye model, i.e., without any interactions.

The imaginary part $\varepsilon^{\prime \prime}(\omega)$ vs. the real part $\varepsilon^{\prime}(\omega)$ of the entire complex permittivity of $\mathrm{H}$-titanate recorded at room temperature is plotted in Figure 7A. The quasi-vertical straight line fitted below $3 \cdot 10^{5} \mathrm{~Hz}$ represents the first relaxation P1. The real part of the permittivity is superior to $10^{5}$ at $50 \mathrm{~Hz}$ due to the capacitive effect at the sample/silver interface (Figure S6). This interface is partially blocking and ohmic contact, including the resistive part due to limited charge flow and the capacitive part due to interface polarization. P1 corresponds to the high-frequency part of quasi-Debye relaxation which is described in the function above. ${ }^{64,65}$ The contribution of directcurrent conductivity is also present.

As P1 shows a strong amplitude, the entire complex permittivity needed to be decomposed to separate and identify the different relaxations. Upon subtraction of $\mathrm{P} 1$, a second relaxation P2 (Figure 7B) is well fitted with the Cole-Cole function with a relaxation frequency $v_{2}=9.3 \cdot 10^{5} \mathrm{~Hz}$. Using the same procedure, by subtracting subsequently lower frequency contributions, P3 (Figure 7C), P4 (Figure 7D), and P5 (Figure 7E) are also well fitted using the Cole-Cole function, respectively at $v_{3}$ $=1.1 \cdot 10^{7} \mathrm{~Hz}, v_{4}=1.6 \cdot 10^{8} \mathrm{~Hz}$ and $v_{5}=2.2 \cdot 10^{9} \mathrm{~Hz}$.

Each frequency or relaxation is associated with a particular microscopic mechanism spanning grain polarization (low frequency) to ion jump (intermediate frequency) to free water rotation (high frequency). ${ }^{66}$
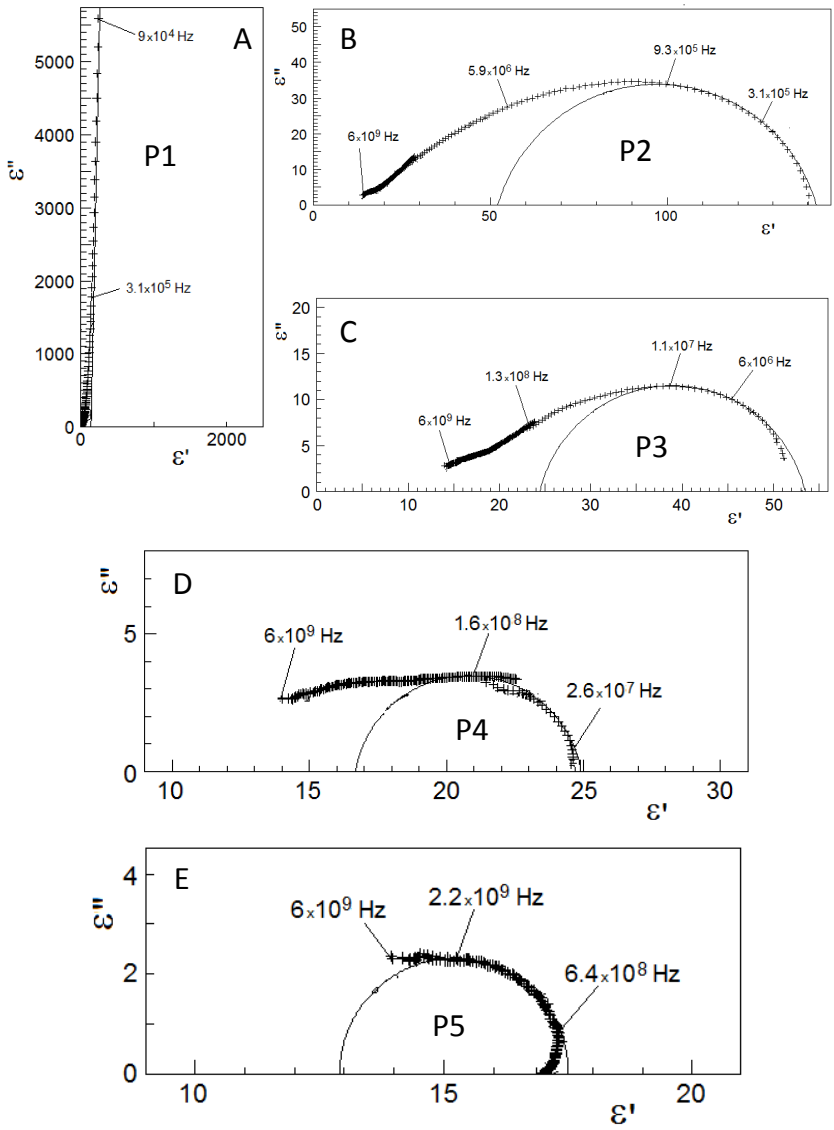

Figure 7. Plots of the imaginary part $\varepsilon$ ' $(\omega)$ vs. the real part $\varepsilon^{\prime}(\omega)$ of the complex permittivity of H-titanate measured at $295 \mathrm{~K}$ : (A) Entire plot, (B) Plot obtained after subtraction of P1, (C) then 
after subtraction of P2, (D) then after subtraction of P3 and E) finally after subtraction of $\mathrm{P} 4$.

Concerning P2 and P3, the observed frequencies are typical of grain polarization. The occurrence of two frequencies can be explained by morphological features. Indeed, previous work on molybdenum oxide showed that the frequencies of relaxation of aggregate and nanobelts presented distinct values with $7 \cdot 10^{5} \mathrm{~Hz}$ for the aggregate and $2 \cdot 10^{7} \mathrm{~Hz}$ for the nanobelt. ${ }^{64}$ Overall, the polarization of grains is affected by the scale of the ionic density inhomogeneity. We previously observed that the solid was built from aggregates composed of fibers. As the conductivity of aggregates is lower than that of fibers, the dielectric relaxation of aggregates arises at a lower frequency. ${ }^{67}$ Therefore, P2 and P3 are reasonably attributed to the relaxations of aggregate and fibers, respectively.

The frequencies associated with P4 and P5 are typical of ionic jump associated with proton mobility and interlayer water dipole reorientation, respectively. Indeed, the previous investigation reported relaxation frequencies of $18 \cdot 10^{9} \mathrm{~Hz}$ for free water, $4 \cdot 10^{9} \mathrm{~Hz}$ for interlayer water in $\mathrm{V}_{2} \mathrm{O}_{5}$ xerogel, and $1.3 \cdot 10^{3} \mathrm{~Hz}$ for ice $(\mathrm{T}=250 \mathrm{~K}){ }^{68,69}$ The relaxation frequency P5 $\left(v_{5}=2.2 \cdot 10^{9} \mathrm{~Hz}\right)$ is much lower than that of free water or interlayer water confined in $\mathrm{V}_{2} \mathrm{O}_{5}$ but higher than ice. Lower relaxation frequency of P5 can be explained by steric hindrance induced by the trititanate structure and also due to strong H-bonding as shown by ${ }^{1} \mathrm{H}$ NMR and FT-IR spectroscopy. Badot et al, ${ }^{70}$ showed that the relaxation frequency of interlayer water in the presence of $\mathrm{H}_{3} \mathrm{O}^{+}$is slowed down to the order of $10^{9} \mathrm{~Hz}$. Hence, we assigned P5 to the interlayer water dipole reorientation.

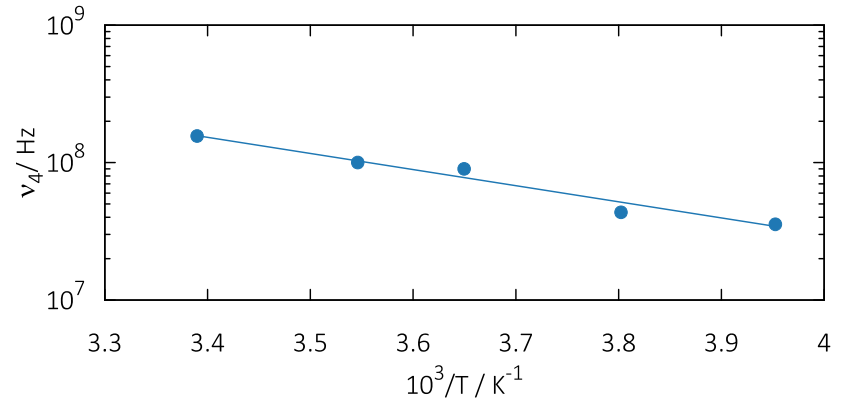

Figure 8. Arrhenius plot of relaxation frequencies of $\mathrm{P} 4$ associated with proton ionic motion. The activation energy deduced from the plot is $0.24 \mathrm{eV}$.

By attributing subsequently P3 and P5 relaxations, P4 is attributed to ionic motions of protons/hydroniums stabilized in the trititanate structure and giving rise to the measured high ionic conductivity. To further characterize proton mobility in the structure, we plotted an Arrhenius-based law representing the evolution of the relaxation frequencies as a function of the inverse of temperature ( $295 \mathrm{~K}-253 \mathrm{~K}$ ) (Figure 8 ). The linear relationship indicates that proton mobility is a thermally activated process with an activation energy of $0.24 \mathrm{eV}$. Remarkably, this value is similar to the one obtained with the bulk conductivity (Table S2, Figure S7) showing that ionic mobility within the trititanate structure is dominated by protons.

The mechanism by which ionic mobility occurs within the trititanate structure involved water and hydronium ions located within the interlayer space. The occurrence of $\mathrm{H}$-bonding suggested that proton mobility involved a Grotthuss-based mechanism through $\mathrm{H}^{+}$-hops ${ }^{71}$ rather than a vehicle mechanism of $\mathrm{H}_{3} \mathrm{O}^{+}$as found in $\mathrm{H}_{3} \mathrm{OUO}_{2} \mathrm{AsO}_{4} \cdot 3 \mathrm{H}_{2} \mathrm{O}$ (HUAs). ${ }^{72}$

\section{Structural modeling and proton-hopping mechanism}

To better understand the atomic structure and ionic transport within the H-trititanate, we used density functional theory (DFT) calculations. We first built a supercell starting from the structure determined by PDF refinement, in which we added the likely positions of hydronium ions. To simplify the calculations, water molecules - expected to be present within the structure-were omitted. The resulting supercell $\mathrm{Ti}_{12} \mathrm{O}_{28}\left(\mathrm{H}_{3} \mathrm{O}\right)_{8}$ was simulated using a triclinic unit cell defined by $a=15.777 \AA, b=3.858 \AA, c=9.398 \AA, \alpha=90.000^{\circ}, \beta$ $=101.500^{\circ}$, and $\gamma=90.000^{\circ}$ (Figure 9, left). At the surface of each titanate layer, oxygen is found in one of two coordination environments: one-fold (Figure 9, green) or two-fold coordinated (Figure 9, purple). Hydronium ions were initially placed roughly halfway between the two titanate layers and in alignment with each surface oxygen atom without particular attention to the initial orientation.

The relaxed structure of the titanate shows a strong ordering of the hydronium ions. In each of the two local environments, a reorientation of $\mathrm{H}_{3} \mathrm{O}^{+}$is observed forming a line of molecules bridging the two adjacent titanate layers via hydrogen bonding with either the one-fold or two-fold coordinated oxygen atoms. The hydronium ion coordinated to the one-fold oxygen (Figure 9, green inset) is composed of two longer bonds oriented towards the oxygen atom $(\sim 1.10-1.16 \AA)$, and one which is oriented away with a slightly shorter bond (0.97-1.06 $\AA$ ) interacting with the opposing titanate layer. Protons on the hydronium ion sit roughly $1.5 \AA$ from the titanate layer. The hydronium ions that interact with the two-fold coordinated oxygens, however, show a less consistent set of bond lengths and vary based on each ion's local environment. Bond lengths of these ions are generally a shorter bond around $0.99 \AA$ and two longer bonds around $1.06 \AA$. Protons fall roughly $1.25 \AA$ from the titanate surface. 

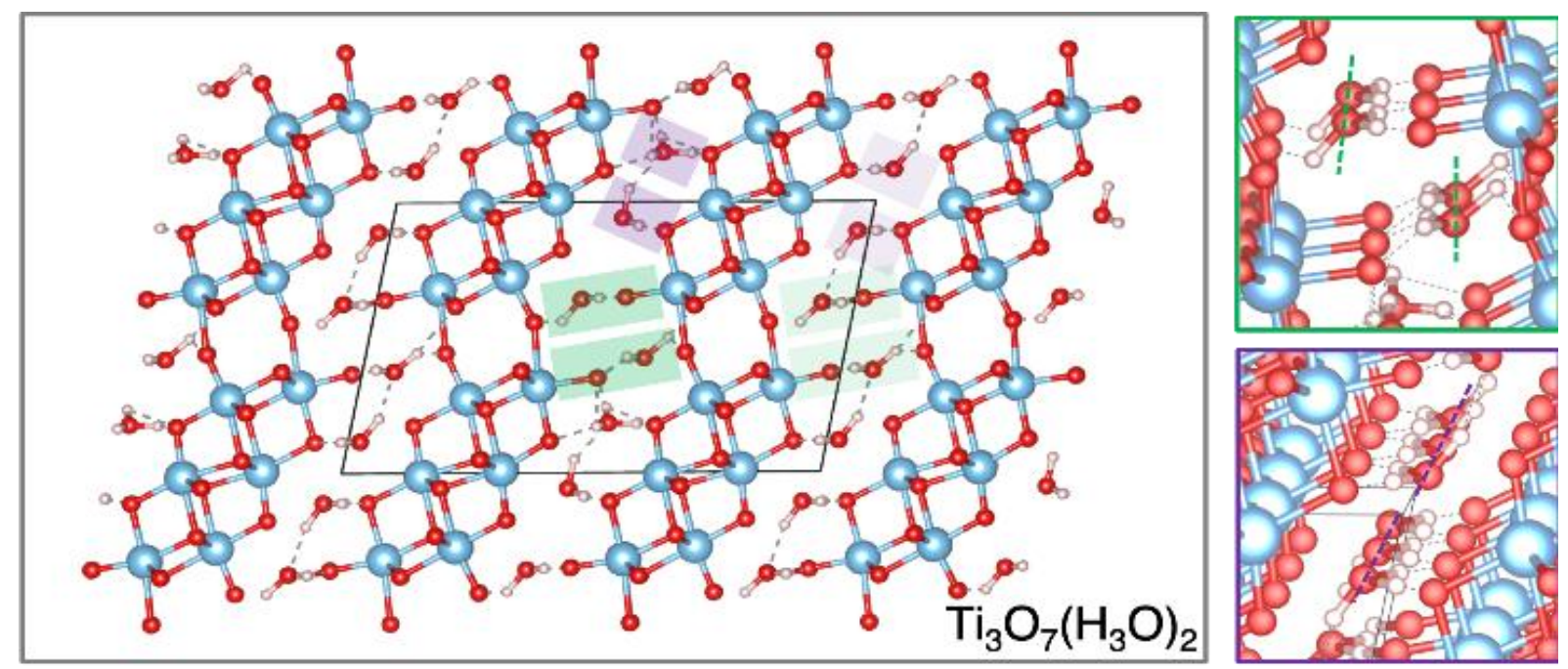

Figure 9. The relaxed $\mathrm{Ti}_{12} \mathrm{O}_{28}\left(\mathrm{H}_{3} \mathrm{O}\right)_{8}$ supercell computed using density functional theory. The hydronium ions fall either next to a one-fold coordinated oxygen atom (green) or two-fold coordinated oxygen atoms (purple). Insets to the right show an alternative perspective illustrating the lines of hydronium atoms that are parallel to the surface of the titanate layers and the hydrogen bonds that are on either side of the hydronium ions.

The relaxed structure provides some insight into the likely mechanism for proton diffusion in the structure. Given the arrangement of the hydronium ions in the interlayer plane, proton diffusion likely occurs in this two-dimensional plane. To consider the possible role that the equilibrium position of the hydronium ions plays in proton mobility in the titanate structure, we define a path between the oxygen of a hydronium ion and the one-fold coordinated oxygen (highlighted in green in Figure 9) with a distance of $2.55 \AA$ A. The path is divided into seventeen steps for which the total energy of the system is recomputed as the proton advances between the two oxygens. Figure 10 shows the total energy profile for the proton transfer from hydronium to titanate in purple where the minimum energy of the path is shifted to zero. The total energy of the system varies very little as the proton moves between the two oxygens. As a result, protons are similarly likely to be found at either site.

Given the ease of which the proton moves between the hydronium and titanate oxygen, we investigate a proton transfer between a hydronium ion and an adjacent water molecule resulting from the protonation of titanate oxygen as described in the previous step. The distance between hydronium ion and the water oxygen is $2.61 \AA$, which for the relaxed structure is the most similar distance as compared to the distance between the hydronium and the surface oxygens of the titanate layer. The hydroxyl group on the titanate oxygen has a bond length of $1.01 \AA$. The total energy profile in Figure 10 which characterizes the differences in the energy of the system as the surface of the titanate is protonated shows an essentially barrierless transition. Thus, proton transfer between hydronium ions is also possible as the surface oxygens likely also play a role in facilitating the movement of protons throughout the material and ultimately enhancing proton conductivity as proton acceptors. Moreover, water molecules absent from the model used in the DFT calculations yet present in the synthesized materials may also appear at a similar distance and thus play a similar role.

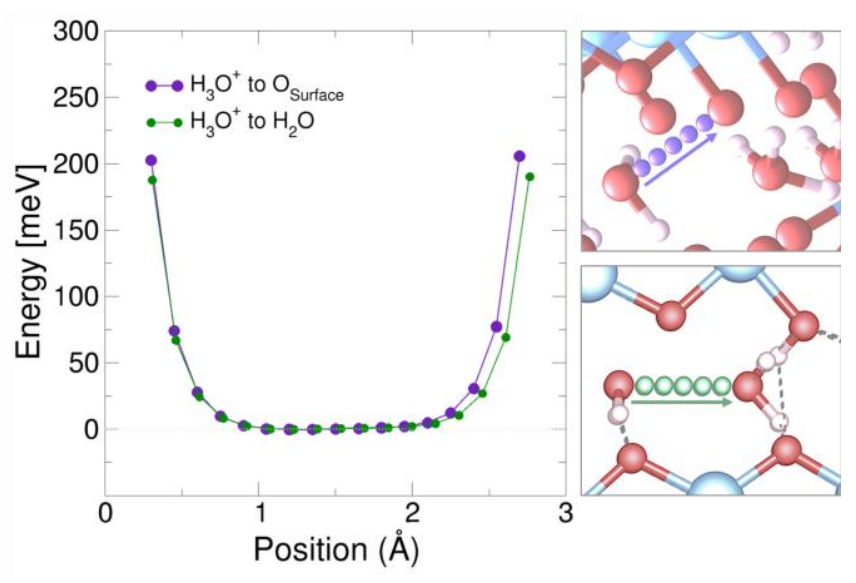

Figure 10. The total energy profile for the proton transfer between a hydronium ion and a one-fold coordinated oxygen in the titanate layer (purple) and between two hydronium ions (green). Each curve is shifted such that the minimum energy along the path is $0 \mathrm{meV}$. The paths for each proton transfer event are shown on the right.

\section{Electrochemistry}

It is well accepted that upon applying a negative bias to a $\mathrm{TiO}_{2}$ electrode in a strong acidic media $(\mathrm{pH}<2$; free protons i.e., $\mathrm{H}_{3} \mathrm{O}^{+}$) or in acetic acid $\left(\mathrm{AH} ; \mathrm{A}^{-} \equiv \mathrm{CH}_{3} \mathrm{COO}^{-}\right.$) solution (weak acid), protons can intercalate within the $\mathrm{TiO}_{2}$ lattice according to following reactions: ${ }^{18,73}$

$\mathrm{Ti}^{\mathrm{IV}} \mathrm{O}_{2}$ (surface) $+x \mathrm{H}^{+}\left(\mathrm{H}_{3} \mathrm{O}^{+}\right.$or $\left.\mathrm{AH}\right)+x \mathrm{e}^{-} \leftrightarrow \mathrm{Ti}^{\mathrm{III}} \mathrm{OOH}$ (surface) $+\mathrm{H}_{2} \mathrm{O}$ (or $\mathrm{A}^{-}$)

$\mathrm{Ti}^{\mathrm{iII}} \mathrm{OOH}$ (surface) $+\mathrm{Ti}^{\mathrm{IV}} \mathrm{O}_{2}$ (bulk) $\leftrightarrow \mathrm{Ti}^{\mathrm{IV}} \mathrm{O}_{2}$ (surface) + $\mathrm{Ti}^{\text {III }} \mathrm{OOH}$ (bulk)

The former equation represents the charge transfer at the electrode/electrolyte interface and the later represents the propagation of $\mathrm{Ti}^{\mathrm{III}}$ sites throughout the oxide lattice via $\mathrm{H}^{+}$hop- 
ping. ${ }^{18,72}$ Therefore, proton conductivity in the $\mathrm{TiO}_{2}$ lattice is crucial to achieving good capacity (i.e., to intercalate a high mole fraction of protons in $\mathrm{TiO}_{2}$ lattice), especially at high
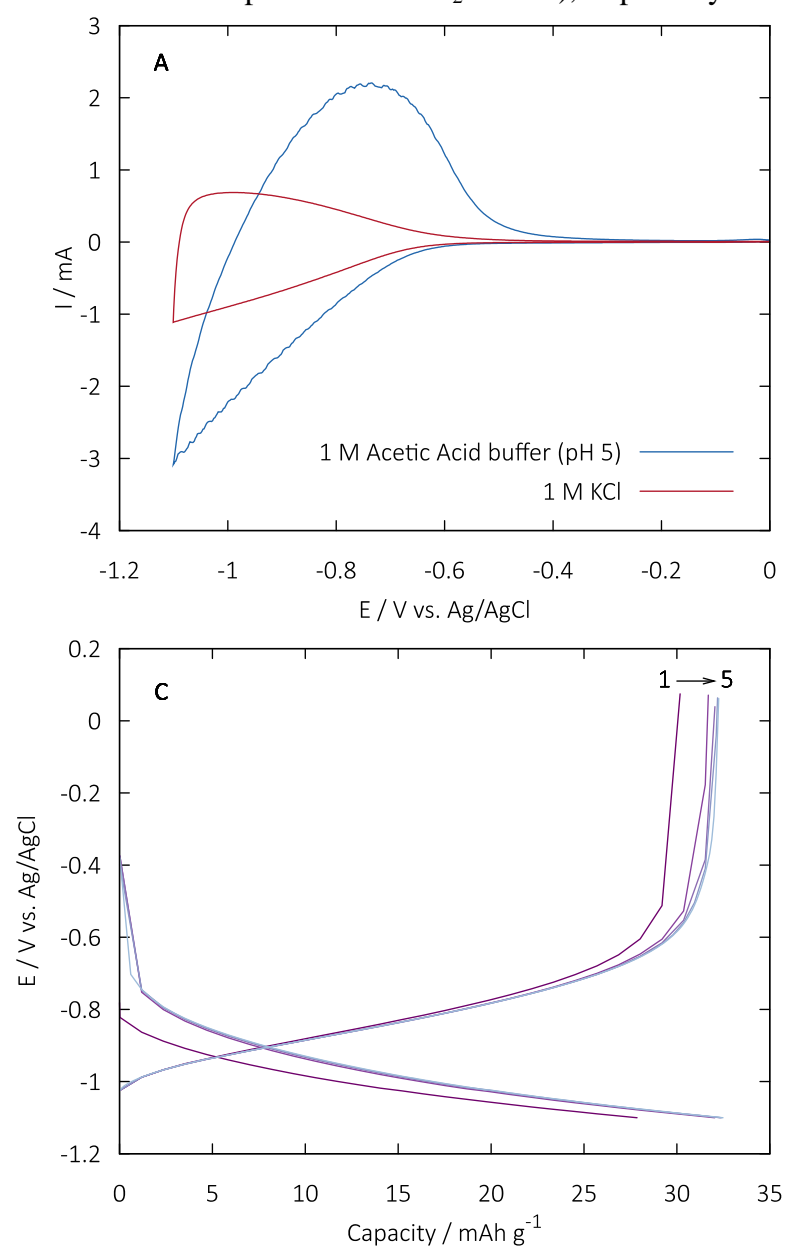

currents. The intrinsic $\mathrm{H}^{+}$-mobility within the H-titanate compound thus motivated us to probe its electrochemical properties with respect to the proton as a charge carrier.
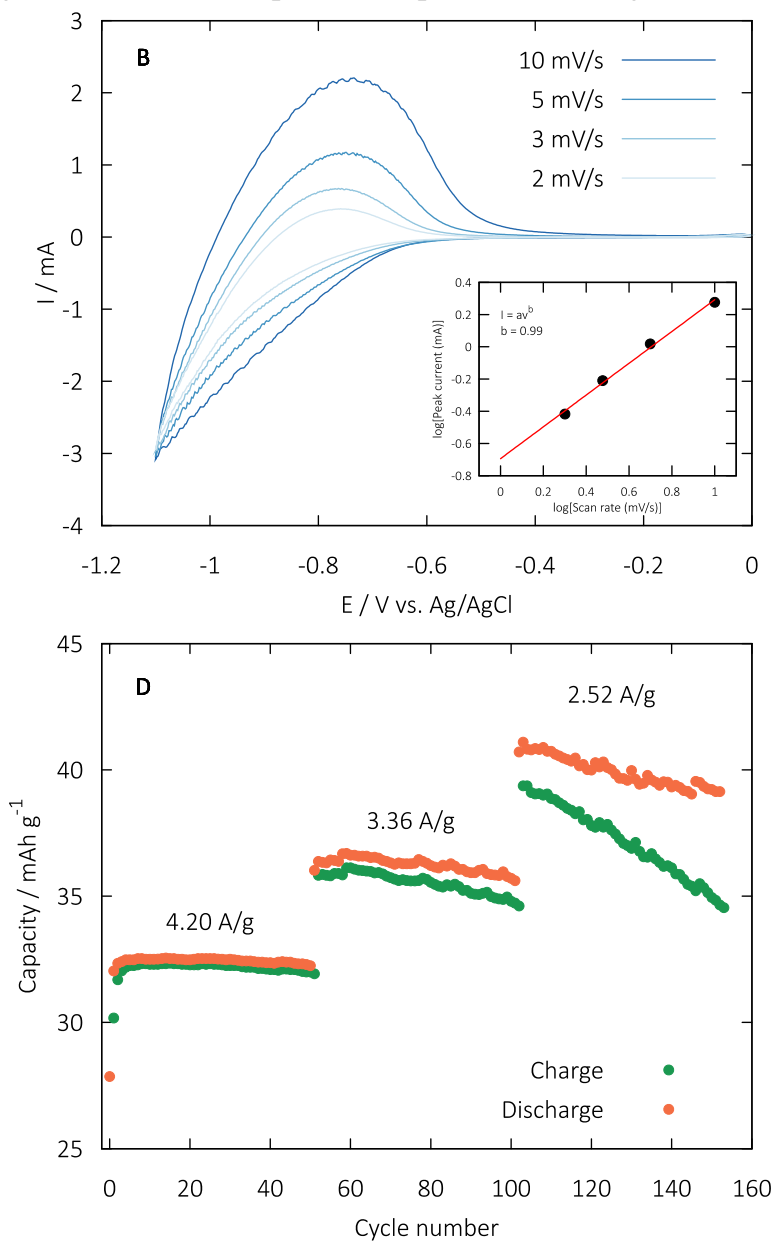

Figure 11. A) CVs for $\mathrm{H}$-titanate recorded at $10 \mathrm{mV} / \mathrm{s}$ in $1 \mathrm{M} \mathrm{KCl}$ and $1 \mathrm{M}$ acetate buffer, B) CVs at different scan rates for $\mathrm{H}$-titanate in 1 $\mathrm{M}$ acetate buffer. The inset to Figure 11b shows logarithmic of peak currents vs. logarithmic of square root of scan rates, C) Galvanostatic charge-discharge curves for $\mathrm{H}$-titanate in $1 \mathrm{M}$ acetate buffer under $4.2 \mathrm{~A} / \mathrm{g}$, D) cycling of $\mathrm{H}$-titanate in $1 \mathrm{M}$ acetate buffer under 4.2 , 3.36 and

$\mathrm{An} \mathrm{Ag} / \mathrm{AgCl}$ (saturated $\mathrm{KCl} ;+0.2 \mathrm{~V}$ vs. $\mathrm{NHE}$ at $25^{\circ} \mathrm{C}$ ) and a $\mathrm{Pt}$ wire were used as the reference and counter electrode, respectively. We used $1 \mathrm{M} \mathrm{KCl}(\mathrm{pH} \leq 7)$ and $1 \mathrm{M}$ acetate $\left(\mathrm{CH}_{3} \mathrm{COOH} / \mathrm{CH}_{3} \mathrm{COOK}\right)$ buffer solution $(\mathrm{pH}=5)$ as electrolytes. The former contains a very low concentration of protons (Note: $\mathrm{H}_{2} \mathrm{O}$ donates protons under extreme basic conditions; $\left.\mathrm{pK}_{\mathrm{a}}\left(\mathrm{H}_{2} \mathrm{O}\right) \geq 14\right)$ whereas acetic acid is a monoprotic organic acid having a $\mathrm{pK}_{\mathrm{a}}$ of 4.76 and capable of donating/accepting protons at $\mathrm{pH}=5$ as reported previously. ${ }^{43}$ The selection of these two electrolytes thus allows us to distinguish the faradaic and capacitive behavior of the electrode material. To minimize the contribution from hydrogen evolution reaction at the electrode, the cut-off voltage was fixed at $-1.1 \mathrm{~V}$. Figure $11 \mathrm{~A}$ shows cyclic voltammetry $(\mathrm{CV})$ curves for $\mathrm{H}$-titanate collected at $10 \mathrm{mV} / \mathrm{s}$ in $1 \mathrm{M} \mathrm{KCl}$ and $1 \mathrm{M}$ acetate buffer. The H-titanate electrode exhibits a negligible current between 0 to $-0.66 \mathrm{~V}$ (approx.) in both electrolytes. This is because the electronic properties of the amorphous $\mathrm{TiO}_{2}$ are characterized by a $\mathrm{pH}$ dependent conduction band potential of $\mathrm{E}_{\mathrm{CB}}=-0.36-0.06 \times$ $\mathrm{pH}$ (V vs. $\mathrm{Ag} / \mathrm{AgCl}) .{ }^{18,43}$ Therefore, similar to $\mathrm{TiO}_{2}, \mathrm{H}$-titanate exhibits poor electronic conductivity (insulator) as long as the applied potential $\mathrm{E} \gg \mathrm{E}_{\mathrm{CB}}\left(\mathrm{E}_{\mathrm{CB}}\right.$ is expected between -0.66 to -
$0.78 \mathrm{~V}$ for the present case at $\mathrm{pH}$ between 5-7). A transition from an insulating to a conducting state occurs at $\mathrm{E} \sim \mathrm{E}_{\mathrm{CB}}$, which is associated with the progressive filling of the electronic states within the bandgap and increase of the Fermi level through negative potential scan until $\mathrm{E}<\mathrm{E}_{\mathrm{CB}}$. We observed the insulator to metal transition at a potential below $-0.6 \mathrm{~V}$ (vs. $\mathrm{Ag} / \mathrm{AgCl}$ ) in both electrolytes. Therefore, in $1 \mathrm{M} \mathrm{KCl}$, the $\mathrm{H}-$ titanate electrode possesses a nearly rectangular shaped current response (double-layer capacitance) at a potential below $0.6 \mathrm{~V}$. The negative charge accumulated at $\mathrm{E}<-0.6 \mathrm{~V}$ is compensated by the electrosorption of cations in $1 \mathrm{M} \mathrm{KCl}$. However, in $1 \mathrm{M}$ acetate buffer, the shape and magnitude of the $\mathrm{CV}$ current are strongly modified and a very broad and reversible wave appeared on top of the capacitive current (band-filling). This wave can be reasonably ascribed to the reversible faradaic reduction of $\mathrm{Ti}^{\mathrm{IV}}$ sites due to the intercalation of protons into $\mathrm{H}$-titanate lattice in $1 \mathrm{M}$ acetate buffer, quite similar to what was previously reported for amorphous $\mathrm{TiO}_{2}{ }^{18,43}$ Figure 11B shows $\mathrm{CV}$ s for $\mathrm{H}$-titanate collected at different scan rates in $1 \mathrm{M}$ acetate buffer and a plot in the inset shows logarithmic of oxidation peak currents vs. logarithmic of scan rates. As cathodic peaks are broad and not well-defined, we have plot- 
ted the oxidation peak (centered at $\sim 0.75 \mathrm{~V}$ ) currents $\log \left(\mathrm{I}_{\mathrm{pa}}\right)$ vs $\log (v)$. The observed linear relation between $\log \left(\mathrm{I}_{\mathrm{pa}}\right)$ and $\log (v)$ with the exponent $\mathrm{b}=0.99\left(\mathrm{I}_{\mathrm{pa}}=\mathrm{a} v^{\mathrm{b}}\right)$ indicates the occurrence of a faradaic process, which is not rate-limited by diffusionbased mechanism; ${ }^{9,74}$ in contrary to conventional faradaic/intercalation reactions. ${ }^{75}$ The fast proton intercalation is due to the presence of structural $\mathrm{H}_{2} \mathrm{O} / \mathrm{H}_{3} \mathrm{O}^{+}$for $\mathrm{H}$-titanate; similar to what is reported for Prussian blue analogues thus highlights the beneficial use of intrinsic proton conductivity. ${ }^{9}$

The $\mathrm{CV}$ results thus suggest that when $\mathrm{E}<\mathrm{E}_{\mathrm{CB}}, \mathrm{H}$-titanate gives capacitance due to electrosorption mainly $(14.13 \mathrm{mAh} / \mathrm{g}$ at $10 \mathrm{mV} / \mathrm{s}$ ) when there is a very low concentration of available protons $(\mathrm{KCl})$ whereas it delivers faradaic capacity $(40.47$ $\mathrm{mAh} / \mathrm{g}$ at $10 \mathrm{mV} / \mathrm{s}$ ) when the concentration of available protons is reasonably high (acetic acid). Based on the chemical formula, the calculated theoretical capacity relying on $\mathrm{H}^{+}$intercalation and the involvement of the $\mathrm{Ti}^{\mathrm{IV}} / \mathrm{Ti}^{\mathrm{III}}$ redox couple is $261 \mathrm{mAh} / \mathrm{g}$, which translated to $0.46 \mathrm{H}^{+}$inserted per formula unit for the faradaic capacity. Figure $11 \mathrm{C}$ shows the galvanostatic charge-discharge (GCD) curves obtained at a high current density of $4.2 \mathrm{~A} / \mathrm{g}$. The observed GCD curves in Figure $11 \mathrm{C}$ exhibit a broad potential range for $\mathrm{H}^{+}$intercalation/de-intercalation rather than well-defined plateaus; very similar to what we observed in CVs. The galvanostatic measurements provide a gravimetric capacity of around $33 \mathrm{mAh} / \mathrm{g}$ $\left(0.38 \mathrm{H}^{+}\right.$per formula unit) with Coulombic efficiency (C.E.) $\geq$ $99 \%$ over 50 cycles. The recorded time to obtain these capacities is typically in the order of 25-30 s, emphasizing fast redox reactions. Such a high kinetic might be due to high intrinsic proton mobility of the pristine material.

The C.E. during galvanostatic cycling is found to decrease at lower current density rates (Figure 11D). For instance, under $2.52 \mathrm{~A} / \mathrm{g}$, the observed initial C.E. is $\sim 97 \%$ (with a discharge capacity of $41 \mathrm{mAh} / \mathrm{g}$ ), which is decreased to $87 \%$ over 50 cycles. This decrease in C.E. at current density is possibly linked to the competitive $\mathrm{H}_{2}$ evolution reaction occurring at the electrode. The contribution from the $\mathrm{H}_{2}$ evolution reaction seems to become significant at lower current density as the electrode is bound to spend relatively more time at negative potentials. Therefore, the proposed $\mathrm{H}$-titanate material could be used as a negative electrode material for developing high rate proton-based batteries in mild aqueous electrolytes. However, we believe that with the use of surface protecting layers, this material would be able to deliver high reversible capacity even at low current density. Further works should be performed to confirm this.

\section{CONCLUSION}

We synthesized layered titanate by revisiting the Kasuga method using molecular Ti(IV) instead of solid precursors. The obtained enhanced reactivity of the titanium precursor enabled to obtain Na-titanate at low temperature under hydrothermal condition followed by $\mathrm{Na}^{+}-\mathrm{H}^{+}$ionic exchange reaction. The obtained $\mathrm{H}$-titanate featured an $\mathrm{x}$-ray diffraction powder pattern consisting of broad Bragg peaks indicating nanosized/disordered structure. Microscopy analysis showed that the morphology of the solid consists of a 2-3 nm thin elongated particles. Real-space refinement of the pair distribution function identified the tetragonal trititanate structure. The determination of the phase composition yielded $\left(\mathrm{H}_{3} \mathrm{O}\right)_{1.35} \mathrm{Ti}_{3} \mathrm{O}_{6.67} \square_{0.33} \cdot 1.73 \mathrm{H}_{2} \mathrm{O}$ pointing to a large presence of hydronium ions and water molecules located within the interlayer space. Solid-state ${ }^{1} \mathrm{H}$ NMR emphasized that the reso- nances of $\mathrm{H}_{3} \mathrm{O}^{+}$ions and $\mathrm{H}_{2} \mathrm{O}$ molecules displayed close isotropic chemical shift values with broad features due to the rapid exchange of protons between these species. Broadband dielectric spectroscopy confirmed the occurrence of high proton mobility with a conductivity of $4 \cdot 10^{-2} \mathrm{~S} / \mathrm{m}$ which is the highest value reported for this type of material. A low activation energy of $0.24 \mathrm{eV}$ indicated that proton species can diffuse easily throughout the network. DFT-calculations rationalized the observed high proton conductivity with a model system suggesting barrierless proton transfer occurring from hydronium ions toward the titanate framework and within the interlayer space, consistent with a Grotthuss-based mechanism. The electrochemical properties with respect to the proton as a charge carrier were investigated using a proton-free $(\mathrm{KCl})$ and proton-donor (buffer acetic acid) electrolytes. $\mathrm{Cy}$ clic voltammetry indicated the occurrence of a faradaic process rate-limited controlled by surface adsorption of $\mathrm{H}$ titanate. Galvanostatic experiments showed that the structure can reversibly insert proton under high rate (25-30 s per discharge/charge) opening perspectives for the development of a high-power negative electrode for aqueous proton batteries.

\section{ASSOCIATED CONTENT}

\section{Supporting Information}

Additional data: SEM, PDF, conductometric titration, XRDs and broadband dielectric spectroscopy can be found in Supporting Information, available free of charge on the ACS Publications website.

\section{AUTHOR INFORMATION}

\section{Corresponding Author \\ *damien.dambournet@sorbonne-universite.fr}

\section{Funding Sources}

A.S and C.L.R acknowledge the French agency of research (ANR) for funding through contract ANR-18-CE05-0014-02.

\section{ACKNOWLEDGMENT}

The work done at the Advanced Photon Source, an Office of Science User Facility operated for the U.S. Department of Energy (DOE) Office of Science by Argonne National Laboratory, was supported by the U.S. DOE under contract no. DE-AC0206CH11357. We thank IMPC FR2482 for SEM-FEG and TEM instrumentation funded by CNRS, Sorbonne Université and C'Nano projects of Région Ile-de-France.

\section{REFERENCES}

(1) Ong, S. P.; Chevrier, V. L.; Hautier, G.; Jain, A.; Moore, C.; Kim, S.; Ma, X.; Ceder, G. Voltage, Stability and Diffusion Barrier Differences between Sodium-Ion and Lithium-Ion Intercalation Materials. Energy Environ. Sci. 2011, 4 (9), 3680. https://doi.org/10.1039/c1ee01782a.

(2) Yabuuchi, N.; Kubota, K.; Dahbi, M.; Komaba, S. Research Development on Sodium-Ion Batteries. Chem. Rev. 2014, 114 (23), 11636-11682. https://doi.org/10.1021/cr500192f.

(3) Komaba, S.; Hasegawa, T.; Dahbi, M.; Kubota, K. Potassium Intercalation into Graphite to Realize High-Voltage/High-Power Potassium-Ion Batteries and Potassium-Ion Capacitors. Electrochem. Commun. 2015, 60, 172-175. https://doi.org/10.1016/j.elecom.2015.09.002.

(4) Aurbach, D.; Lu, Z.; Schechter, A.; Gofer, Y.; Gizbar, H.; Turgeman, R.; Cohen, Y.; Moshkovich, M.; Levi, E. Prototype Systems for Rechargeable Magnesium Batteries. Nature 2000, 407 (6805), 724-727. https://doi.org/10.1038/35037553. 
(5) Mohtadi, R.; Mizuno, F. Magnesium Batteries: Current State of the Art, Issues and Future Perspectives. Beilstein J. Nanotechnol. 2014, 5, 1291-1311. https://doi.org/10.3762/bjnano.5.143.

(6) See, K. A.; Gerbec, J. A.; Jun, Y.-S.; Wudl, F.; Stucky, G. D.; Seshadri, R. A High Capacity Calcium Primary Cell Based on the Ca-S System. Adv. Energy Mater. 2013, 3 (8), 1056-1061. https://doi.org/10.1002/aenm.201300160.

(7) Ponrouch, A.; Frontera, C.; Bardé, F.; Palacín, M. R. Towards a Calcium-Based Rechargeable Battery. Nat. Mater. 2016, 15 (2), 169-172. https://doi.org/10.1038/nmat4462.

(8) Emanuelsson, R.; Sterby, M.; Strømme, M.; Sjödin, M. An All-Organic Proton Battery. J. Am. Chem. Soc. 2017, 139 (13), 48284834. https://doi.org/10.1021/jacs.7b00159.

(9) Wu, X.; Hong, J. J.; Shin, W.; Ma, L.; Liu, T.; Bi, X.; Yuan, Y.; Qi, Y.; Surta, T. W.; Huang, W.; Neuefeind, J.; Wu, T.; Greaney, P. A.; Lu, J.; Ji, X. Diffusion-Free Grotthuss Topochemistry for High-Rate and Long-Life Proton Batteries. Nat. Energy 2019, 4 (2), 123-130. https://doi.org/10.1038/s41560-018-0309-7.

(10) Sun, W.; Wang, F.; Hou, S.; Yang, C.; Fan, X.; Ma, Z.; Gao, T.; Han, F.; Hu, R.; Zhu, M.; Wang, C. Zn/MnO 2 Battery Chemistry With $\mathrm{H}^{+}$and $\mathrm{Zn}^{2+}$ Coinsertion. J. Am. Chem. Soc. 2017, 139 (29), 9775-9778. https://doi.org/10.1021/jacs.7b04471.

(11) Zhao, Q.; Liu, L.; Yin, J.; Zheng, J.; Zhang, D.; Chen, J.; Archer, L. A. Proton Intercalation/De- Intercalation Dynamics in Vanadium Oxides for Aqueous Aluminum Electrochemical Cells. Angew. Chem. Int. Ed. 2020, 59 (8), 3048-3052. https://doi.org/10.1002/anie.201912634.

(12) Jiang, H.; Shin, W.; Ma, L.; Hong, J. J.; Wei, Z.; Liu, Y.; Zhang, S.; Wu, X.; Xu, Y.; Guo, Q.; Subramanian, M. A.; Stickle, W. F.; Wu, T.; Lu, J.; Ji, X. A High- Rate Aqueous Proton Battery Delivering Power Below $-78{ }^{\circ} \mathrm{C}$ via an Unfrozen Phosphoric Acid. Adv. Energy Mater. 2020, $10 \quad$ (28), 2000968. https://doi.org/10.1002/aenm.202000968.

(13) Fattakhova-Rohlfing, D.; Zaleska, A.; Bein, T. ThreeDimensional Titanium Dioxide Nanomaterials. Chem. Rev. 2014, 114 (19), 9487-9558. https://doi.org/10.1021/cr500201c.

(14) Ghicov, A.; Tsuchiya, H.; Hahn, R.; Macak, J. M.; Muñoz, A. G.; Schmuki, P. $\mathrm{TiO}_{2}$ Nanotubes: $\mathrm{H}^{+}$Insertion and Strong Electrochromic Effects. Electrochem. Commun. 2006, 8 (4), 528-532. https://doi.org/10.1016/j.elecom.2006.01.015.

(15) Berger, T.; Anta, J. A.; Morales-Flórez, V. Spectroscopic Properties of Electrochemically Populated Electronic States in Nanostructured $\mathrm{TiO}_{2}$ Films: Anatase versus Rutile. Phys. Chem. $\begin{array}{lllll}\text { Chem. } & \text { Phys. } & \text { 2013, } & 15 & \text { (33), }\end{array}$ https://doi.org/10.1039/c3cp52324a.

(16) Berger, T.; Anta, J. A.; Morales-Flórez, V. Electrons in the Band Gap: Spectroscopic Characterization of Anatase $\mathrm{TiO}_{2}$ Nanocrystal Electrodes under Fermi Level Control. J. Phys. Chem. C 2012, 116 (21), 11444-11455. https://doi.org/10.1021/jp212436b.

(17) Berger, T.; Monllor-Satoca, D.; Jankulovska, M.; LanaVillarreal, T.; Gómez, R. The Electrochemistry of Nanostructured Titanium Dioxide Electrodes. ChemPhysChem 2012, 13 (12), 2824 2875. https://doi.org/10.1002/cphc.201200073.

(18) Kim, Y.-S.; Kriegel, S.; Harris, K. D.; Costentin, C.; Limoges, B.; Balland, V. Evidencing Fast, Massive, and Reversible $\mathrm{H}^{+}$ Insertion in Nanostructured $\mathrm{TiO}_{2}$ Electrodes at Neutral PH. Where Do Protons Come From? J. Phys. Chem. C 2017, 121 (19), 10325-10335. https://doi.org/10.1021/acs.jpcc.7b02395.

(19) Fleischmann, S.; Sun, Y.; Osti, N. C.; Wang, R.; Mamontov, E.; Jiang, D.; Augustyn, V. Interlayer Separation in Hydrogen Titanates Enables Electrochemical Proton Intercalation. J. Mater. Chem. A 2019, 8 (1), 412-421. https://doi.org/10.1039/C9TA11098D.

(20) Fleischmann, S.; Spencer, M. A.; Augustyn, V. Electrochemical Reactivity under Confinement Enabled by Molecularly Pillared 2D and Layered Materials. Chem. Mater. 2020, 32 (8), 33253334. https://doi.org/10.1021/acs.chemmater.0c00648.

(21) Kreuer, K.-D. Proton Conductivity: Materials and Applications. Chem. Mater. 1996, 8 (3), 610-641. https://doi.org/10.1021/cm950192a.
(22) Thorne, A.; Kruth, A.; Tunstall, D.; Irvine, J. T. S.; Zhou, W. Formation, Structure, and Stability of Titanate Nanotubes and Their Proton Conductivity. J. Phys. Chem. B 2005, 109 (12), 54395444. https://doi.org/10.1021/jp047113f.

(23) Yamada, M.; Wei, M.; Honma, I.; Zhou, H. OneDimensional Proton Conductor under High Vapor Pressure Condition Employing Titanate Nanotube. Electrochem. Commun. 2006, 8 (9), 1549-1552. https://doi.org/10.1016/j.elecom.2006.07.020.

(24) Hu, W.; Li, L.; Li, G.; Meng, J.; Tong, W. Synthesis of Titanate-Based Nanotubes for One-Dimensionally Confined Electrical Properties. J. Phys. Chem. C 2009, 113 (39), 16996-17001. https://doi.org/10.1021/jp907001n.

(25) Kasuga, T.; Hiramatsu, M.; Hoson, A.; Sekino, T.; Niihara, K. Titania Nanotubes Prepared by Chemical Processing. Adv. Mater. 1999, 11 (15), 1307-1311. https://doi.org/10.1002/(SICI)15214095(199910)11:15<1307::AID-ADMA1307>3.0.CO;2-H

(26) Chen, Q.; Zhou, W.; Du, G.; Peng, L.-M. Trititanate Nanotubes Made via a Single Alkali Treatment. Adv. Mater. 2002, 14 (17), $1208-1211$. https://doi.org/10.1002/1521 4095(20020903)14:17<1208::AID-ADMA1208>3.0.CO;2-0.

(27) Wu, D.; Liu, J.; Zhao, X.; Li, A.; Chen, Y.; Ming, N. Sequence of Events for the Formation of Titanate Nanotubes, Nanofibers, Nanowires, and Nanobelts. Chem. Mater. 2006, 18 (2), 547-553. https://doi.org/10.1021/cm0519075.

(28) Fleischmann, S.; Spencer, M. A.; Augustyn, V. Electrochemical Reactivity under Confinement Enabled by Molecularly Pillared 2D and Layered Materials $\dagger$. Chem. Mater. 2020. https://doi.org/10.1021/acs.chemmater.0c00648.

(29) Uppuluri, R.; Gupta, A. S.; Rosas, A. S.; Mallouk, T. E. Soft Chemistry of Ion-Exchangeable Layered Metal Oxides. Chem. $\begin{array}{lllll}\text { Soc. } & \text { Rev. } & \mathbf{2 0 1 8}, & 47 & \text { (7), }\end{array}$ https://doi.org/10.1039/C7CS00290D.

(30) Muñoz-Santiburcio, D.; Wittekindt, C.; Marx, D. Nanoconfinement Effects on Hydrated Excess Protons in Layered Materials. Nat. Commun. 2013, $4 \quad$ (1), 2349. https://doi.org/10.1038/ncomms3349.

(31) Muñoz-Santiburcio, D.; Marx, D. Chemistry in Nanoconfined Water. Chem. Sci. 2017, 8 (5), 3444-3452. https://doi.org/10.1039/C6SC04989C.

(32) Tunuguntla, R. H.; Allen, F. I.; Kim, K.; Belliveau, A.; Noy, A. Ultrafast Proton Transport in Sub-1-Nm Diameter Carbon Nanotube Porins. Nat. Nanotechnol. 2016, 11 (7), 639-644. https://doi.org/10.1038/nnano.2016.43.

(33) Augustyn, V.; Gogotsi, Y. 2D Materials with Nanoconfined Fluids for Electrochemical Energy Storage. Joule 2017, 1 (3), 443452. https://doi.org/10.1016/j.joule.2017.09.008.

(34) Mitchell, J. B.; Geise, N. R.; Paterson, A. R.; Osti, N. C.; Sun, Y.; Fleischmann, S.; Zhang, R.; Madsen, L. A.; Toney, M. F.; Jiang, D.; Kolesnikov, A. I.; Mamontov, E.; Augustyn, V. Confined Interlayer Water Promotes Structural Stability for High-Rate Electrochemical Proton Intercalation in Tungsten Oxide Hydrates. ACS Energy Lett. 2019, 4 (12), 2805-2812. https://doi.org/10.1021/acsenergylett.9b02040.

(35) Hammersley, A. P.; Svensson, S. O.; Hanfland, M.; Fitch, A. N.; Hausermann, D. Two-Dimensional Detector Software: From Real Detector to Idealised Image or Two-Theta Scan. High Press. Res. 1996, 14 (4-6), 235-248. https://doi.org/10.1080/08957959608201408.

(36) Juhás, P.; Davis, T.; Farrow, C. L.; Billinge, S. J. L. PDFgetX3 : A Rapid and Highly Automatable Program for Processing Powder Diffraction Data into Total Scattering Pair Distribution Functions. J. Appl. Crystallogr. 2013, 46 (2), 560-566. https://doi.org/10.1107/S0021889813005190.

(37) Farrow, C. L.; Juhas, P.; Liu, J. W.; Bryndin, D.; Božin, E. S.; Bloch, J.; Proffen, T.; Billinge, S. J. L. PDFfit2 and PDFgui: Computer Programs for Studying Nanostructure in Crystals. J. Phys. Condens. Matter 2007, 19 (33), 335219. https://doi.org/10.1088/09538984/19/33/335219.

(38) Massiot, D.; Fayon, F.; Capron, M.; King, I.; Le Calvé, S.; Alonso, B.; Durand, J.-O.; Bujoli, B.; Gan, Z.; Hoatson, G. Modelling 
One- and Two-Dimensional Solid-State NMR Spectra. Magn. Reson. Chem. 2002, 40 (1), 70-76. https://doi.org/10.1002/mrc.984.

(39) Hutter, J.; Iannuzzi, M.; Schiffmann, F.; VandeVondele, J. CP2K: Atomistic Simulations of Condensed Matter Systems. Wiley Interdiscip. Rev. Comput. Mol. Sci. 2014, 4 (1), 15-25. https://doi.org/10.1002/wcms.1159.

(40) VandeVondele, J.; Hutter, J. Gaussian Basis Sets for Accurate Calculations on Molecular Systems in Gas and Condensed Phases. J. Chem. Phys. 2007, 127 (11), 114105. https://doi.org/10.1063/1.2770708.

(41) Goedecker, S.; Teter, M.; Hutter, J. Separable Dual-Space Gaussian Pseudopotentials. Phys. Rev. B 1996, 54 (3), 1703-1710. https://doi.org/10.1103/PhysRevB.54.1703.

(42) Perdew, J. P.; Burke, K.; Ernzerhof, M. Generalized Gradient Approximation Made Simple. Phys. Rev. Lett. 1996, 77 (18), 3865-3868. https://doi.org/10.1103/PhysRevLett.77.3865.

(43) Kim, Y.-S.; Harris, K. D.; Limoges, B.; Balland, V. On the Unsuspected Role of Multivalent Metal Ions on the Charge Storage of a Metal Oxide Electrode in Mild Aqueous Electrolytes. Chem. Sci. 2019, 10 (38), 8752-8763. https://doi.org/10.1039/C9SC02397F.

(44) Kasuga, T.; Hiramatsu, M.; Hoson, A.; Sekino, T.; Niihara, K. Formation of Titanium Oxide Nanotube. Langmuir 1998, 14 (12), 3160-3163. https://doi.org/10.1021/la9713816.

(45) Ma, R.; Bando, Y.; Sasaki, T. Nanotubes of Lepidocrocite Titanates. Chem. Phys. Lett. 2003, 380 (5-6), 577-582. https://doi.org/10.1016/j.cplett.2003.09.069.

(46) Tsai, C.-C.; Teng, H. Structural Features of Nanotubes Synthesized from $\mathrm{NaOH}$ Treatment on $\mathrm{TiO}_{2}$ with Different PostTreatments. Chem. Mater. 2006, 18 (2), 367-373. https://doi.org/10.1021/cm0518527.

(47) Sasaki, T.; Watanabe, M.; Michiue, Y.; Komatsu, Y.; Izumi, F.; Takenouchi, S. Preparation and Acid-Base Properties of a Protonated Titanate with the Lepidocrocite-like Layer Structure. Chem. Mater. 1995, 7 (5), 1001-1007. https://doi.org/10.1021/cm00053a029.

(48) Kataoka, K.; Kijima, N.; Akimoto, J. Ion-Exchange Synthesis, Crystal Structure, and Physical Properties of Hydrogen Titanium Oxide $\mathrm{H}_{2} \mathrm{Ti}_{3} \mathrm{O}_{7}$. Inorg. Chem. 2013, 52 (24), 13861-13864. https://doi.org/10.1021/ic401144k.

(49) Christiansen, T. L.; Cooper, S. R.; Jensen, K. M. Ø There's No Place like Real-Space: Elucidating Size-Dependent Atomic Structure of Nanomaterials Using Pair Distribution Function Analysis. Nanoscale Adv. 2020, 2 (6), 2234-2254. https://doi.org/10.1039/D0NA00120A.

(50) Billinge, S. J. L.; Kanatzidis, M. G. Beyond Crystallography: The Study of Disorder, Nanocrystallinity and Crystallographically Challenged Materials with Pair Distribution Functions. Chem. Commun. 2004, No. 7, 749 https://doi.org/10.1039/b309577k.

(51) Gateshki, M.; Chen, Q.; Peng, L.-M.; Chupas, P.; Petkov, V. Structure of Nanosized Materials by High-Energy X-Ray Diffraction: Study of Titanate Nanotubes. Z. Für Krist. - Cryst. Mater. 2007, 222 (11/2007). https://doi.org/10.1524/zkri.2007.222.11.612.

(52) Feist, T. P.; Davies, P. K. The Soft Chemical Synthesis of $\mathrm{TiO}_{2}$ (B) from Layered Titanates. J. Solid State Chem. 1992, 101 , 275-295. https://doi.org/10.1016/0022-4596(92)90184-W.

(53) Armstrong, A. R.; Armstrong, G.; Canales, J.; Bruce, P. G. $\mathrm{TiO}_{2}-\mathrm{B}$ Nanowires. Angew. Chem. Int. Ed. 2004, 43 (17), 2286-2288. https://doi.org/10.1002/anie.200353571.

(54) Wu, Y.; Yu, J.; Liu, H.-M.; Xu, B.-Q. One-Dimensional $\mathrm{TiO}_{2}$ Nanomaterials: Preparation and Catalytic Applications. $J$. Nanosci. Nanotechnol. 2010, 10 (10), 6707-6719. https://doi.org/10.1166/jnn.2010.2531.

(55) Zhu, G.-N.; Wang, C.-X.; Xia, Y.-Y. Structural Transformation of Layered Hydrogen Trititanate $\left(\mathrm{H}_{2} \mathrm{Ti}_{3} \mathrm{O}_{7}\right)$ to $\mathrm{TiO}_{2}(\mathrm{~B})$ and Its Electrochemical Profile for Lithium-Ion Intercalation. J. Power $\begin{array}{llll}\text { Sources } & \mathbf{2 0 1 1}, & 196 & \text { (5), }\end{array}$ https://doi.org/10.1016/j.jpowsour.2010.07.023.

(56) Lei, Y.; Sun, J.; Liu, H.; Cheng, X.; Chen, F.; Liu, Z. Atomic Mechanism of Predictable Phase Transition in Dual-Phase $\mathrm{H}_{2} \mathrm{Ti}_{3} \mathrm{O}_{7} / \mathrm{TiO}_{2}$ (B) Nanofiber: An In Situ Heating TEM Investigation.
Chem. - Eur. J. 2014, 20 (36), 11313-11317. https://doi.org/10.1002/chem.201403272.

(57) Wang, N.; Lin, H.; Li, J.; Zhang, L.; Lin, C.; Li, X. Crystalline Transition from $\mathrm{H}_{2} \mathrm{Ti}_{3} \mathrm{O}_{7}$ Nanotubes to Anatase Nanocrystallines Under Low-Temperature Hydrothermal Conditions. J. Am. Ceram. Soc. 2006, 89 (11), 3564-3566. https://doi.org/10.1111/j.15512916.2006.01257.x.

(58) Ma, J.; Reeves, K. G.; Porras Gutierrez, A.-G.; Body, M.; Legein, C.; Kakinuma, K.; Borkiewicz, O. J.; Chapman, K. W.; Groult, H.; Salanne, M.; Dambournet, D. Layered Lepidocrocite Type Structure Isolated by Revisiting the Sol-Gel Chemistry of Anatase $\mathrm{TiO}_{2}$ : A New Anode Material for Batteries. Chem. Mater. 2017, 29 (19), 8313-8324. https://doi.org/10.1021/acs.chemmater.7b02674.

(59) Wang, M.; Jaegers, N. R.; Lee, M.-S.; Wan, C.; Hu, J. Z.; Shi, H.; Mei, D.; Burton, S. D.; Camaioni, D. M.; Gutiérrez, O. Y.; Glezakou, V.-A.; Rousseau, R.; Wang, Y.; Lercher, J. A. Genesis and Stability of Hydronium Ions in Zeolite Channels. J. Am. Chem. Soc. 2019, 141 (8), 3444-3455. https://doi.org/10.1021/jacs.8b07969.

(60) Crocker, M.; Herold, R. H. M.; Wilson, A. E.; Mackay, M.; Emeis, C. A.; Hoogendoorn, A. M. 1 H NMR Spectroscopy of Titania. Chemical Shift Assignments for Hydroxy Groups in Crystalline and Amorphous Forms of TiO2. J. Chem. Soc. Faraday Trans. 1996, 92 (15), 2791-2798. https://doi.org/10.1039/FT9969202791.

(61) Beluze, L.; Badot, J. C.; Weil, R.; Lucas, V. Broadband Dielectric and Resistivity Spectroscopy of $\mathrm{WO}_{3} \cdot \mathrm{H}_{2} \mathrm{O}$ in the Range of $10^{3}-10^{10} \mathrm{~Hz}$ : Particle Size Effect. J. Phys. Chem. B 2006, 110 (14), 7304-7308. https://doi.org/10.1021/jp0561524.

(62) Gao, T.; Fjeld, H.; Fjellvåg, H.; Norby, T.; Norby, P. In Situ Studies of Structural Stability and Proton Conductivity of Titanate Nanotubes. Energy Environ. Sci. 2009, 2 (5), 517. https://doi.org/10.1039/b821532b.

(63) Cole, K. S.; Cole, R. H. Dispersion and Absorption in Dielectrics I. Alternating Current Characteristics. J. Chem. Phys. 1941, 9 (4), 341-351. https://doi.org/10.1063/1.1750906.

(64) Berthumeyrie, S.; Badot, J.-C.; Pereira-Ramos, J.-P.; Dubrunfaut, O.; Bach, S.; Vermaut, Ph. Influence of Lithium Insertion on the Electronic Transport in Electroactive $\mathrm{MoO}_{3}$ Nanobelts and Classical Powders: Morphological and Particle Size Effects. J. Phys. Chem. C 2010, $114 \quad$ (46), 19803-19814. https://doi.org/10.1021/jp106837g.

(65) Badot, J.-C.; Lestriez, B.; Dubrunfaut, O. Interest in Broadband Dielectric Spectroscopy to Study the Electronic Transport in Materials for Lithium Batteries. Mater. Sci. Eng. B 2016, 213, 190 198. https://doi.org/10.1016/j.mseb.2016.05.012.

(66) Cadène, A.; Rotenberg, B.; Durand-Vidal, S.; Badot, J.-C.; Turq, P. Dielectric Spectroscopy as a Probe for Dynamic Properties of Compacted Smectites. Phys. Chem. Earth Parts ABC 2006, 31 (10), 505-510. https://doi.org/10.1016/j.pce.2006.04.002.

(67) Badot, J.-C.; Ligneel, É.; Dubrunfaut, O.; Guyomard, D.; Lestriez, B. A Multiscale Description of the Electronic Transport within the Hierarchical Architecture of a Composite Electrode for Lithium Batteries. Adv. Funct. Mater. 2009, 19 (17), 2749-2758. https://doi.org/10.1002/adfm.200900379.

(68) Badot, J. C.; Fourrier-Lamer, A.; Baffier, N. Dielectric Study of $\mathrm{V}_{2} \mathrm{O}_{5}-1.6 \mathrm{H}_{2} \mathrm{O}$ Xerogel in the Broad Frequency Range $\left(10^{5}\right.$ $\left.10^{10} \mathrm{~Hz}\right) . \quad J . \quad$ Phys. 1985, $46 \quad$ (12), 2107-2115. https://doi.org/10.1051/jphys:0198500460120210700.

(69) Buchner, R.; Barthel, J.; Stauber, J. The Dielectric Relaxation of Water between $0{ }^{\circ} \mathrm{C}$ and $35^{\circ} \mathrm{C}$. Chem. Phys. Lett. 1999, $306(1-$ 2), 57-63. https://doi.org/10.1016/S0009-2614(99)00455-8.

(70) Badot, J.-C.; Baffier, N. Ionic Conductivity and Dielectric Properties of Vanadium Pentoxide Xerogels. J. Mater. Chem. 1992, 2, 8. https://doi.org/10.1039/JM9920201167.

(71) Agmon, N. The Grotthuss Mechanism. Chem. Phys. Lett 1995, 244 (5), 456-462. https://doi.org/10.1016/0009-2614(95)00905J.

(72) Kreuer, K. D.; Rabenau, A.; Messer, R. Proton Conductivity in the Layer Compound $\mathrm{H}_{3} \mathrm{OUO}_{2} \mathrm{AsO}_{4} \cdot 3 \mathrm{H}_{2} \mathrm{O}$ (HUAs). Appl. Phys. A 1983, A 32, 45-53. https://doi.org/10.1007/BF00617828. 
(73) Boschloo, G.; Fitzmaurice, D. Electron Accumulation in Nanostructured $\mathrm{TiO}_{2}$ (Anatase) Electrodes. J. Phys. Chem. B 1999, 103 (37), 7860-7868. https://doi.org/10.1021/jp983040m.

(74) Augustyn, V.; Simon, P.; Dunn, B. Pseudocapacitive Oxide Materials for High-Rate Electrochemical Energy Storage. Energy $\begin{array}{llllll}\text { Environ. } & \text { Sci. } & \mathbf{2 0 1 4}, & 7 & \text { (5), } & \text { 1597-1614. }\end{array}$ https://doi.org/10.1039/C3EE44164D.
(75) Lübke, M.; Johnson, I.; Makwana, N. M.; Brett, D.; Shearing, P.; Liu, Z.; Darr, J. A. High Power $\mathrm{TiO}_{2}$ and High Capacity SnDoped $\mathrm{TiO}_{2}$ Nanomaterial Anodes for Lithium-Ion Batteries. J. Power Sources 2015, 294, 94-102. https://doi.org/10.1016/j.jpowsour.2015.06.039.

\section{TOC}

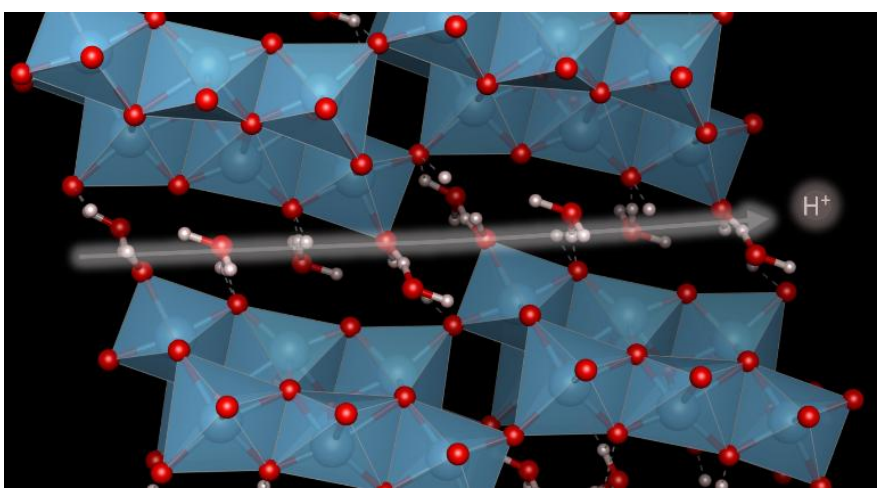

